Nat. Hazards Earth Syst. Sci., 18, 613-631, 2018

https://doi.org/10.5194/nhess-18-613-2018

(C) Author(s) 2018. This work is distributed under the Creative Commons Attribution 4.0 License.

\title{
Physically based approaches incorporating evaporation for early warning predictions of rainfall-induced landslides
}

\author{
Alfredo Reder ${ }^{1,2}$, Guido Rianna ${ }^{2}$, and Luca Pagano ${ }^{1}$ \\ ${ }^{1}$ Department of Civil, Architectural and Environmental Engineering, University of Naples Federico II, 80125 Naples, Italy \\ ${ }^{2}$ Regional Models and geo-Hydrological Impacts Division, CMCC Foundation, 81043 Capua, Italy
}

Correspondence: Guido Rianna (guido.rianna@cmcc.it)

Received: 3 August 2017 - Discussion started: 7 September 2017

Revised: 30 January 2018 - Accepted: 31 January 2018 - Published: 28 February 2018

\begin{abstract}
In the field of rainfall-induced landslides on sloping covers, models for early warning predictions require an adequate trade-off between two aspects: prediction accuracy and timeliness. When a cover's initial hydrological state is a determining factor in triggering landslides, taking evaporative losses into account (or not) could significantly affect both aspects. This study evaluates the performance of three physically based predictive models, converting precipitation and evaporative fluxes into hydrological variables useful in assessing slope safety conditions. Two of the models incorporate evaporation, with one representing evaporation as both a boundary and internal phenomenon, and the other only a boundary phenomenon. The third model totally disregards evaporation. Model performances are assessed by analysing a well-documented case study involving a $2 \mathrm{~m}$ thick sloping volcanic cover. The large amount of monitoring data collected for the soil involved in the case study, reconstituted in a suitably equipped lysimeter, makes it possible to propose procedures for calibrating and validating the parameters of the models. All predictions indicate a hydrological singularity at the landslide time (alarm). A comparison of the models' predictions also indicates that the greater the complexity and completeness of the model, the lower the number of predicted hydrological singularities when no landslides occur (false alarms).
\end{abstract}

\section{Introduction}

In Italy, many sloping deposits of sand or silty sand, constituting covers not exceeding few metres, experience unsaturated conditions throughout the hydrological year. Such state conditions permit them to be stable for slope angles exceeding friction angles (Pagano et al., 2008b) thanks to additional strength provided by suction (usually, they are characterized by low or null true cohesion values). The sequence of rainfall events occurring over the wet season induces a general reduction in suction levels, increasing the cover's susceptibility to an exceptional rainfall event. In contrast, evaporative fluxes reduce susceptibility to sliding by increasing suction levels. The antecedent period, during which the contrast between rainfall and evaporation affects suction levels, may last weeks or months depending on the hydraulic properties of the soils involved and the climate regime of the area (Rahimi et al., 2011; Rahardjo et al., 2001).

The 2005 Nocera Inferiore landslide (hereinafter "2005NIL") was interpreted (Pagano et al., 2010) by merely referring to precipitation recorded by a meteorological station placed near the landslide area (Fig. 1). Richards' (1931) equation in 1-D flow conditions was adopted to convert hourly precipitation records into the evolution of soil suction at various depths. This simple approach highlighted the crucial role of antecedent rainfall $(945 \mathrm{~mm}$ of rainfall over 4.5 months), which had reduced soil suction to very low values before the occurrence of the major event $(143 \mathrm{~mm}$ of rainfall over $16 \mathrm{~h}$ ). Numerical analyses indicate that suction vanishing throughout the entire cover depth can induce the attainment of slope failure conditions. Virtual scenarios built with modified antecedent rainfalls were analysed, and they indicated that the phenomenon would have not occurred if the antecedent periods had been drier. The crucial factor affecting soil suction at triggering time were the weather conditions over the previous 4 months. 


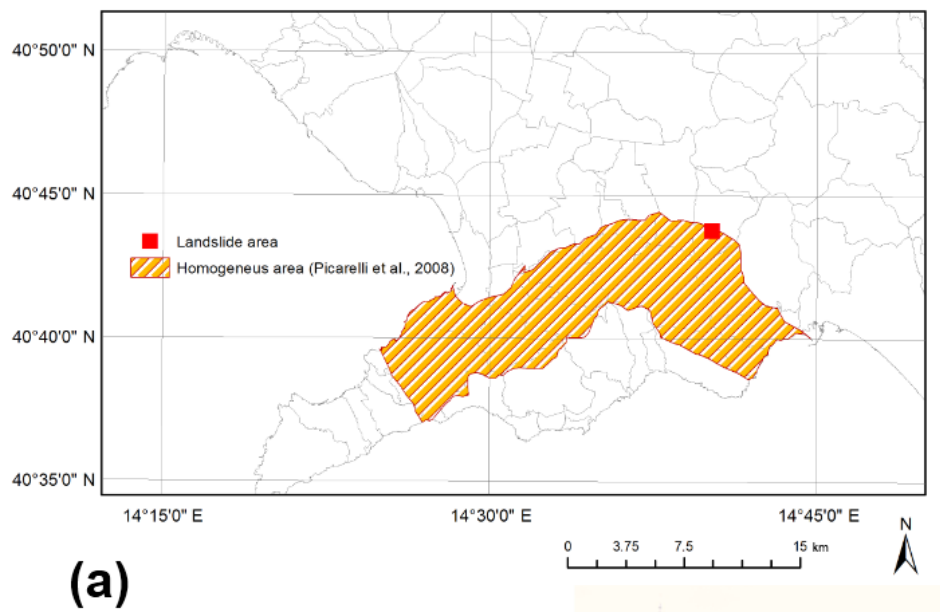

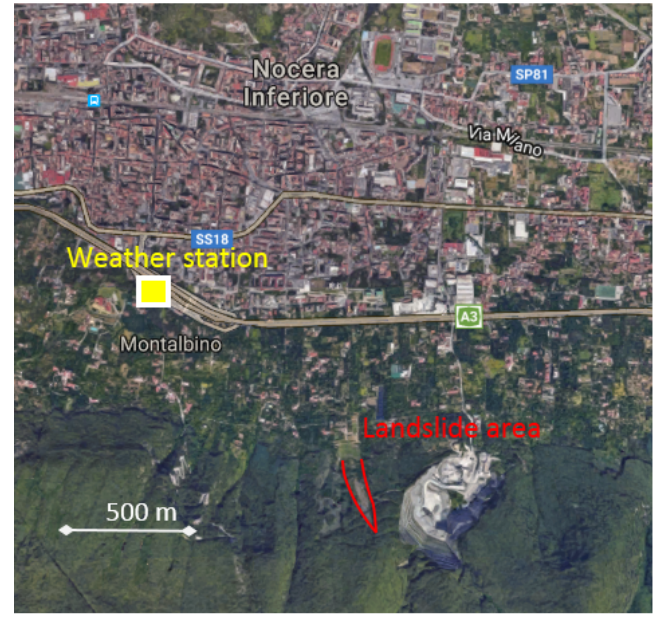

(b)

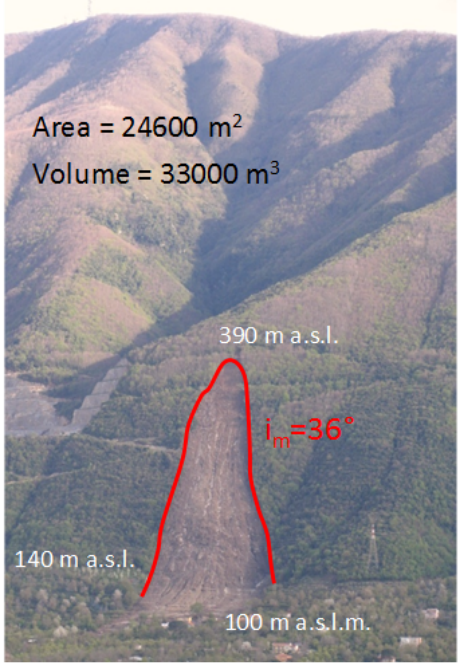

(c)

Figure 1. The 2005 Nocera Inferiore Landslide (2005NIL): (a) map indicating the landslide location and zones homogeneous with that of the landslide for soils, cover thicknesses and slope gradients; (b) plan view (DigitalGlobe 2012, http://www.earth.google.com), indicating the landslide area and the location of the weather station; (c) frontal view of the landslide area (Pagano et al., 2010, modified).

A meteorological window of such long influence implies that it would not be reasonable to neglect evaporative fluxes, as their persistency could result in significant drying processes even during the cold season, when evaporation is at its lowest (about $1-2 \mathrm{~mm} \mathrm{day}^{-1}$ in winter). Rianna et al. (2014a) measured infiltrating precipitation and actual evaporation (AE) induced by the actual weather conditions on a layer placed in a lysimeter, made using the same soil that was involved in the 2005NIL. Monitoring showed that over a hydrological year the amount of AE occurs to the same order of magnitude as that of infiltrating precipitation (hundreds of millimetres).

Increasing efforts are being made to develop early warning systems to mitigate the risks of rainfall-induced landslides. Their success strongly depends on the performance of the predictive models they implement in terms of timing and accuracy of prediction. In tens of centimetres thin and/or coarse-grained soil covers, prediction accuracy does not require an account for evaporation because the latter plays a minor role in the hydrological balance, which might result in a landslide (Brand et al., 1984; Chatterjea, 1989; Morgenstern, 1992).

Thick silty covers may instead experience a hydrological behaviour strongly affected by evaporation. In principle, modelling evaporation requires coupling water and heat flows. Geotechnical engineers and geologists are still too unfamiliar with heat flow modelling in particular, as it entails a number of thermal parameters and boundary conditions that are difficult to calibrate and validate. In addition, governing equations need non-widespread numerical codes and their high non-linearity involves difficulties in achieving numerical solutions. This implies that in several applications evap- 
oration is neglected because it is considered less important than rainfall intensity during a highly intense event that triggered landslides (e.g. Baum et al., 2008; Pagano et al., 2010; Formetta et al., 2016). In other applications evaporation is taken into account by following approaches with different degree of complexity (Casadei et al., 2003; Rosso et al., 2006; Šimunek et al., 2006; Ebel et al., 2010; Formetta et al., 2014; Capparelli and Versace, 2011; Arnone et al., 2011; Endrizzi et al., 2014). Complete approaches, modelling internal and boundary evaporation through hydrothermal approaches, were taken into account in studies referred to slopes in finegrained soils differing substantially from those involved in the case at hand (Cui et al., 2005; An et al., 2017; Song et al., 2016). Concerning the hydrological behaviour of silty volcanic sloping covers, several authors adopted approaches incorporating evaporation for the interpretation of monitoring results (Pirone et al., 2015a) and/or back analysis of previous events (Greco et al., 2013; Napolitano et al., 2016). In such studies, however, evaporative fluxes were modelled as a boundary phenomenon only.

The question naturally arises whether, for silty volcanic sloping covers, the accuracy of the early warning prediction will be significantly reduced if evaporation were neglected, resulting in too many false alarms.

This study attempts to address this question by comparing results yielded by three different mathematical-numerical models, either taking evaporation into account as only superficial or an internal phenomenon (Wilson et al., 1994) or neglecting it (Richards, 1931), in the interpretation of the 2005NIL case study.

Two of the models account for evaporation: one based on a coupled (heat-water flow) approach and the other based on an isothermal approach. The third model neglects evaporation entirely. It represents an update to the approach previously adopted in Pagano et al. (2010). Suction and other hydrological variables predicted by using all the selected models are presented and discussed in an attempt to characterize their various performances.

These three cited models are presumed to be operating in real time, namely receiving recorded and/or forecasted meteorological variables as input data and returning variables relating to slope safety conditions as output data. To this aim, they need to be applied to geomorphological contexts that may be modelled assuming in 1-D flow conditions to save as much analysis time as possible (Pagano et al., 2010; Greco et al., 2013). The paper also discusses which simplifications are able to accelerate predictions without excessively reducing their accuracy.

Considerable effort has been made in this study to develop original procedures for calibrating model parameters from the interpretation of the experimental results provided by the above-mentioned lysimeter. Model parameters are typically quantified in laboratory at a scale much smaller than field conditions. In this perspective, a strength point of the paper is represented by the use, during the calibration and

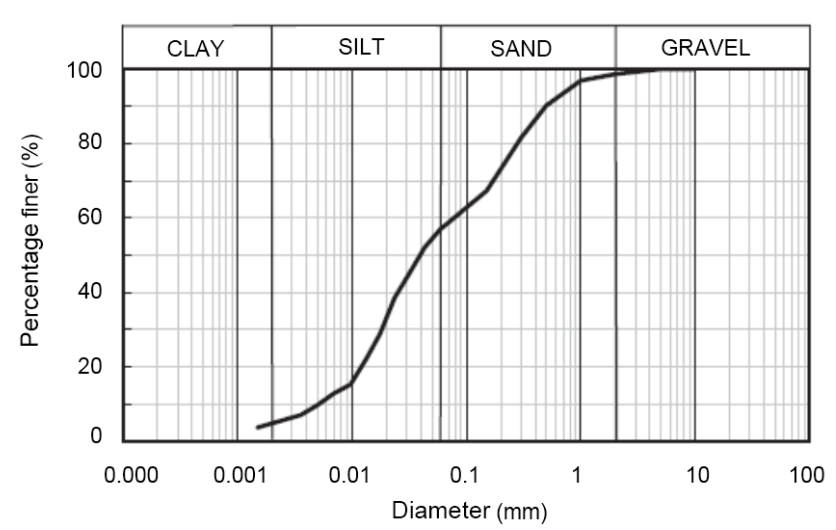

Figure 2. Grain-size distribution of the Nocera Inferiore volcanic ash (Pagano et al., 2010).

validation procedure, of the findings retrieved by the abovementioned lysimeter, involving $1 \mathrm{~m}^{3}$ of material forced by realistic boundary conditions provided by actual meteorological evolution, instead of the traditional procedures based on small specimen subject to artificial boundary conditions. A previous comparison among laboratory, lysimeter and field conditions, restricted to retention properties of the same soil involved in the work (Pirone et al., 2016), resulted in a satisfactory agreement. This encourages throughout the work considering representative lysimeter of field conditions also for quantifying parameters needed to describe soil hydraulic conductivity and thermal behaviour.

The paper begins with a description of the case study and presents the lysimeter data. After describing the selected models and simplifications carried out to save analysis time, it illustrates all the procedures followed to calibrate the parameters. Lastly, it presents and compares the results of the analyses, discussing model performance from the point of view of their possible use as early warning predictors.

\section{Methods}

\subsection{Field experimental data: the Nocera Inferiore 2005 landslide}

2005NIL involved a triangular-shaped area of $24600 \mathrm{~m}^{2}$ and a soil mass of $33000 \mathrm{~m}^{3}$ covering a $36^{\circ}$ open slope (Fig. 1c). In the uppermost part of the landslide, in the triggering zone, the slope angle approaches $39^{\circ}$ (de Riso et al., 2007) and the pyroclastic cover is made up of $2 \mathrm{~m}$ thick loose non-plastic silty sand (volcanic ash) (Fig. 2). The bedrock consists of highly fractured limestone located at a depth ranging from 1 to $2 \mathrm{~m}$, approaching the maximum values at the apical zone.

The landslide triggered in the apical zone, spreading downward. The rapid post-failure movement caused the death of three people whose house was destroyed by the impact of the soil mass, which then covered a wide area 
(a)

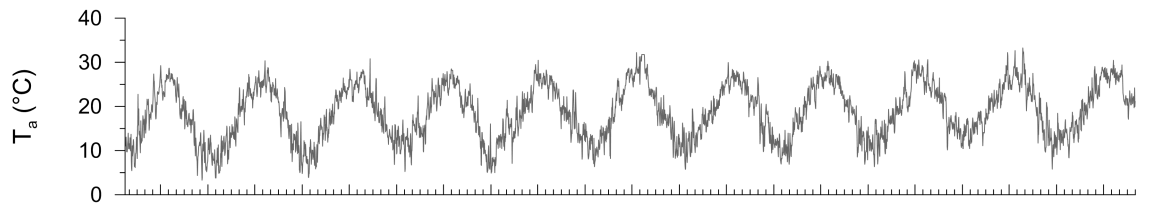

(b)

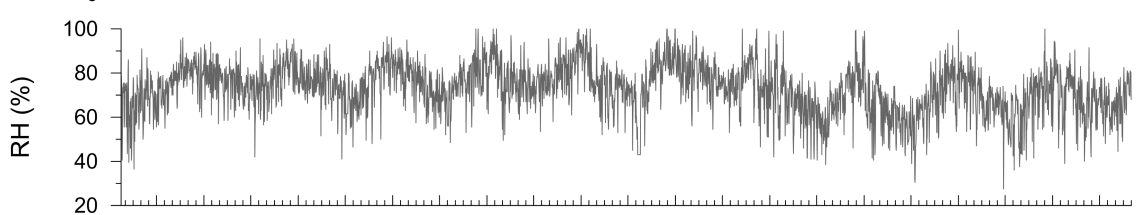

(c)

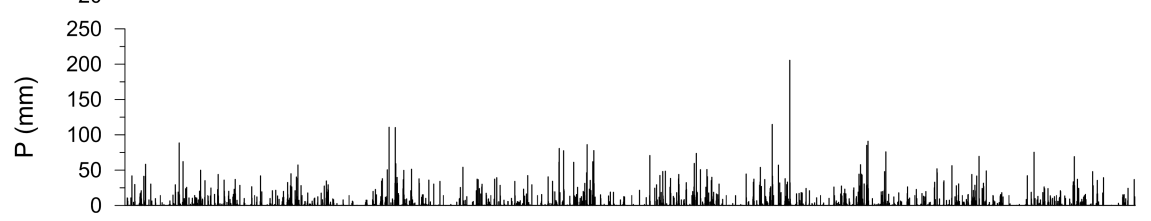

(d)

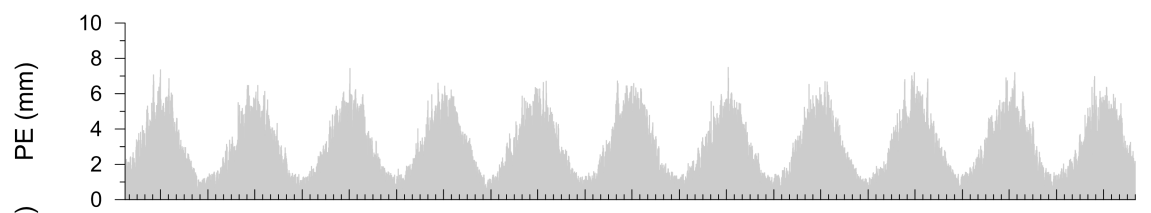

(e)

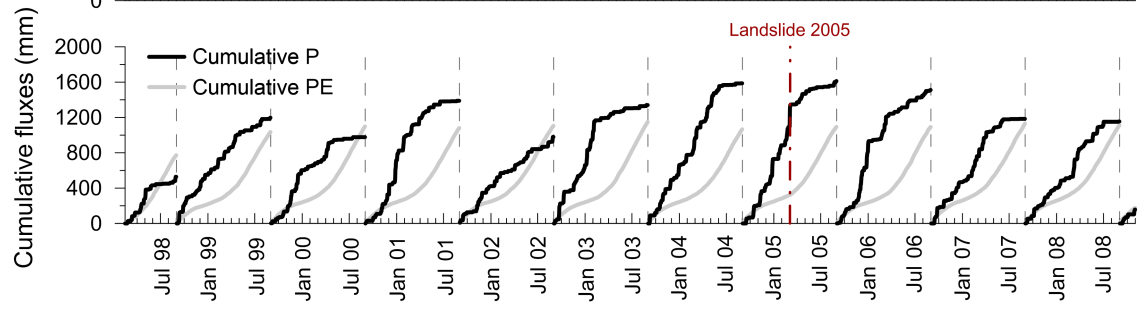

Figure 3. Meteorological variables recorded at the 2005NIL site between January 1998 and August 2008: (a) mean daily air temperature $\left(T_{\mathrm{a}}\right)$; (b) mean daily air relative humidity $(\mathrm{RH})$; (c) daily precipitations $(P)$; (d) daily potential evaporation $(\mathrm{PE})$; (e) precipitation $(P)$ and potential evaporation (PE), cumulated during each hydrological year.

$\left(20000 \mathrm{~m}^{2}\right)$ at the toe of the slope (Fig. 1c). In the same zone, two smaller landslides occurred less than $1 \mathrm{~km}$ from the main one at the same time.

For this case study, in addition to hourly precipitation values, the availability of air relative humidity and air temperature records makes it possible to estimate the evaporative fluxes potentially experienced by the cover involved in the landslide, complementing precipitation in characterizing the fluxes that have affected the hydrological state of the cover over time. Data are retrieved by a weather station located very close to the investigated slope (Fig. 1a). They have an hourly resolution and refer to the timespan 1 January 19981 November 2008.

Figure 3 plots the evolution of precipitation, air temperature and air relative humidity at the landslide site over a time span of about 10 years (1998-2008), including the investigated landslide occurred on 4 March 2005 (precipitation until the landslide time are reported in Pagano et al., 2010). Changes in daily air temperature (Fig. 3a) and air relative humidity (Fig. 3b) are used to estimate the daily potential evaporation (PE) (Fig. 3d) by following the FAO guidelines (Allen et al., 1998). The PE intensities occur much lower than precipitation intensities (Fig. 3c). However, PE persistency makes cumulated values (Fig. 3e) significant even during winter, when the evaporative flux is minimum.

Figure $3 \mathrm{e}$ shows that the hydrological year in which the landslide took place is associated with the highest cumulated precipitation. The most significant spread between cumulated values of precipitation $(1200 \mathrm{~mm})$ and potential evaporation $(380 \mathrm{~mm}$ ) is observed at the time of the landslide (see vertical segment with rows in Fig. 3e).

For the site here considered, monitoring of field hydrological variables was not available to allow for a characterization of safety conditions based on field measurement.

\subsection{Experimental data provided by the physical model}

An extensive description of the physical model and the experimental data used can be found in Rianna et al. (2014a, b). A wooden tank (Fig. 4) houses a $0.75 \mathrm{~m}$ thick layer of nonplastic sandy-silt volcanic soil. This soil was selected and placed in such a way as to try to reproduce the intrinsic properties and field porosities (around 70\%) of the material involved in $2005 \mathrm{NIL}$, the grain-size distribution of which is re- 


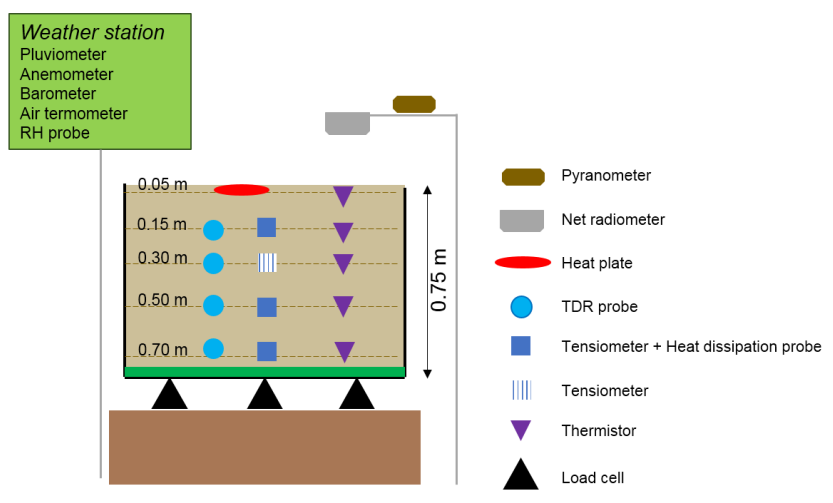

Figure 4. Monitoring devices installed in the physical model (Rianna et al., 2014a, modified).

ported in Fig. 2. A geotextile bounds the bottom of the layer. As its voids are larger than those of the overlying soil, it acts as a capillary barrier, i.e. an impervious boundary as far as suction remains higher than zero, and a draining surface just when suction vanishes (Reder et al., 2017). The behaviour at the bottom should therefore be consistent with that of the fractured bedrock with partly empty fractures or a gravel layer (pumice).

The monitoring system implemented in the physical model (Fig. 4) makes it possible to obtain potential fluxes (total precipitation and potential evaporation), actual fluxes developing across the uppermost layer surface (actual evaporation and infiltrated precipitation) and the effects induced by these fluxes within the layer (suction, volumetric water content, temperature). Fluxes are quantified by a meteorological station, the continuous weighting of the layer (by three load cells sustaining the tank) and monitoring of all the energetic terms involved in the energy exchanges between the soil and atmosphere (by radiometer, pyrometer, heat flux plate, thermistors). Matric suctions (by jet-fill tensiometers and heat dissipation probes), volumetric water contents (using time domain reflectometries, TDRs) and soil temperatures (using thermistors) are monitored at four depths within the layer.

The physical model was exposed to the atmosphere over 4 hydrological years in bare conditions, and it returned a number of behavioural patterns for the evolution of the layer's hydrological and thermal states. These patterns suggest the ingredients that a predictive model should include, allow quantification of soil properties and ultimately represent a useful reference framework to assess reliability of numerical predictions.

The reference behavioural pattern considered here is represented by the evolution of water storage (WS) in the layer (Fig. 5), soil suction (at two depths - Fig. 6a) and temperature (three depths - Fig. 7) over 4 hydrological years (the first 2 years of WS and suction records are by Rianna et al., 2014a; the first 2 years of temperature records are by Rianna et al., 2014b).
WS, expressed in terms of overall water volume in the layer divided by the layer surface (Fig. 5a), increases at the onset of wet periods due to precipitation (Fig. 5b) infiltrating the layer. For prolonged wet periods, such as those occurring during the first, third, and fourth years, WS tends to stabilize at a wet level (Fig. 5a, "wet threshold" line) placed just below the maximum saturation value in the layer (Fig. 5a, "saturation" line). Above this wet level, drainage is often observed during, and immediately after, rainfall events, whereas drainage has never been observed below it. During dry periods, water storage decreases due to evaporation (Fig. 5c), and during prolonged dry periods it tends to reach a minimum at the dry threshold. Soil suction (Fig. 6a) measured at different depths is consistent with water storage evolution (Rianna et al., 2014a). It progressively increases during the dry period, resulting in asynchronous fluctuations, indicating a slow propagation through the sample of the changes in the atmospheric conditions. Suction values exceed the jet-fill tensiometer full scale during the summer periods but reduce to few $\mathrm{kPa}$ during the wet season, resulting in this case in synchronous fluctuations, in line with prompt propagation throughout the layer of changes in boundary conditions determined by the atmosphere.

Temperature (Fig. 7) measured at the four depths follows an evolution consistent with atmospheric temperature. Fluctuations in the temperature of the atmosphere tend to reduce as depth increases due to greater soil filter action.

\subsection{Predictive models}

Three different models (Fig. 8) were selected to convert the meteorological evolution (Fig. 3) recorded at the landslide area into hydrological variables for the cover. Shared features are as follows:

- The one-dimensionality of water fluxes. This hypothesis, formulated in order to save analysis time in early warning applications, should also lead to realistic estimations of the hydrological state of the cover in line with indications of previous works. In particular, according to Pagano et al. (2010) this hypothesis is reliable for homogeneous cover, as 1-D and 2-D numerical analyses yield in this case very comparable results. Reliability should be extended also for the frequent cases of homogeneous layers resting on pumices, as pumices effects may be reduced to suitable boundary conditions (Reder et al., 2017). Papa et al. (2009) observed the onedimensionality of the water flux also throughout layered volcanic slopes, by plotting water flux vectors obtained from field monitoring of suction at the site of Monteforte Irpino. Also, Damiano et al. (2017) confirmed that one-dimensionality of water fluxes is common throughout layered volcanic slopes. On similar geomorphological contexts, Pirone (2009) and Napolitano et al. (2016) model the actual stratigraphy retrievable on field; the former brings to light that extreme wet and dry periods 


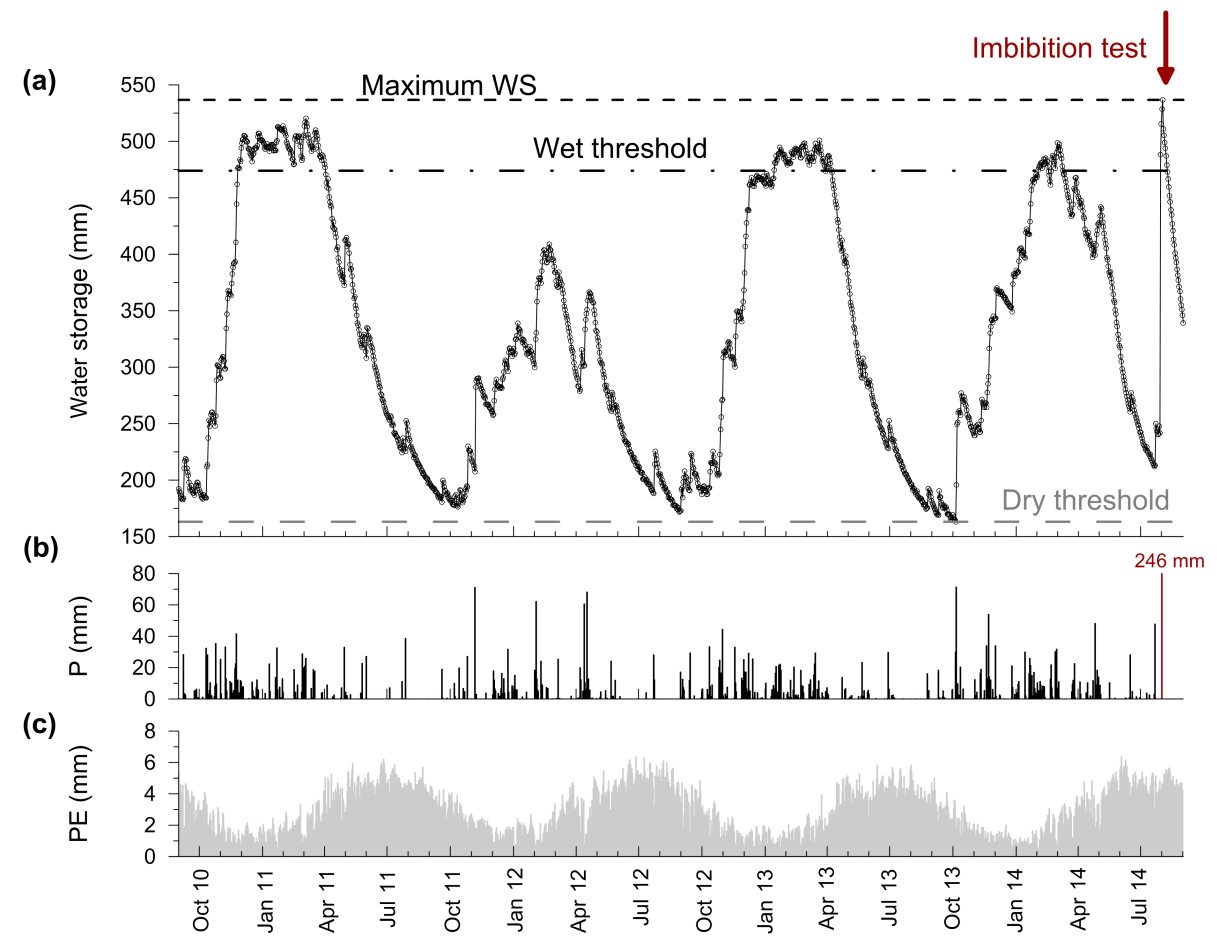

Figure 5. Evolution of variables recorded by the physical model of lysimeter: (a) layer water storage (WS); (b) daily precipitations $(P)$; (c) daily potential evaporation (PE). (Records taken over the first 2 hydrological years are from Rianna et al., 2014a.)

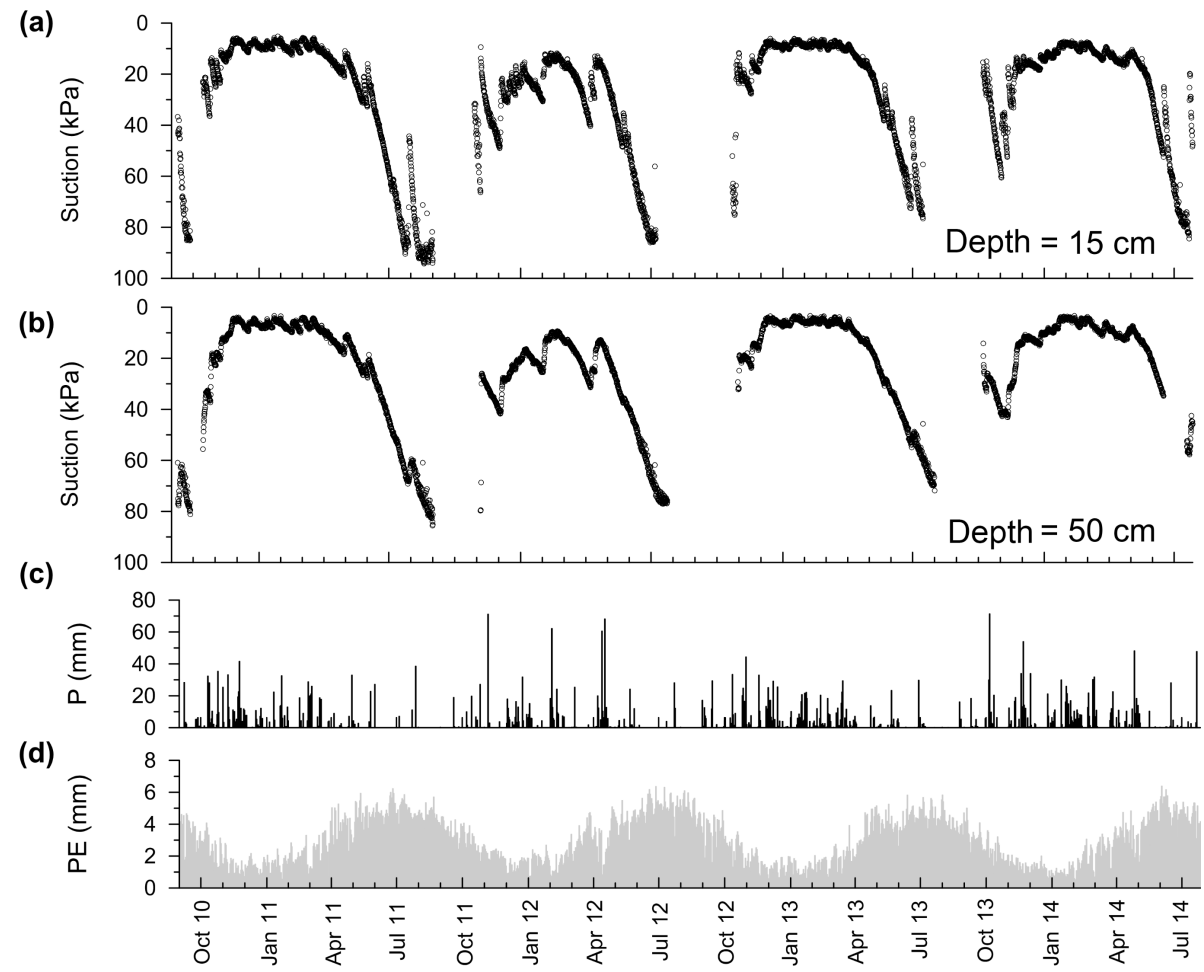

Figure 6. Evolution of variables recorded by the physical model of lysimeter: (a) matric suction at depth of $15 \mathrm{~cm}$; (b) matric suction at depth of $50 \mathrm{~cm}$; (c) daily precipitations $(P)$; (d) daily potential evaporation (PE). (Over the first 2 hydrological years records are from Rianna et al., 2014a.) 
(a)

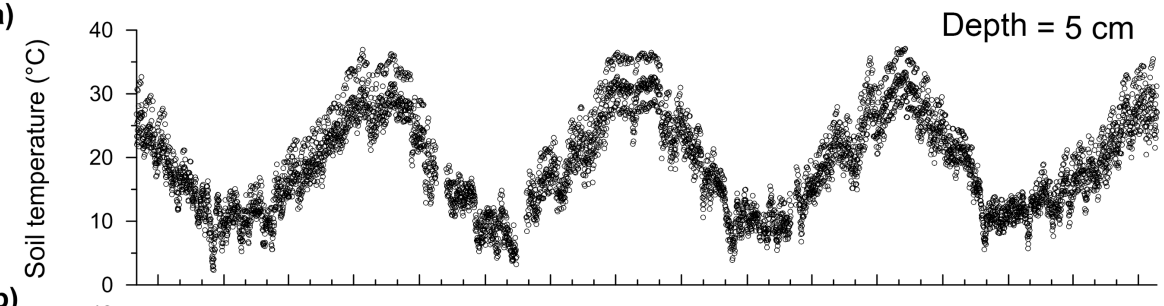

(b)

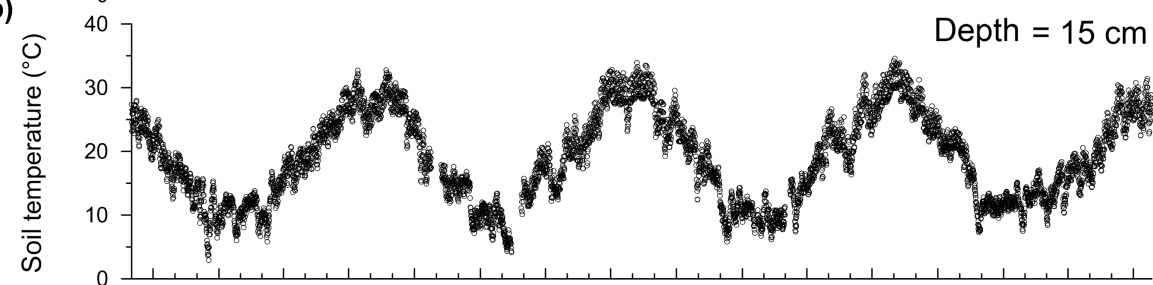

(c)

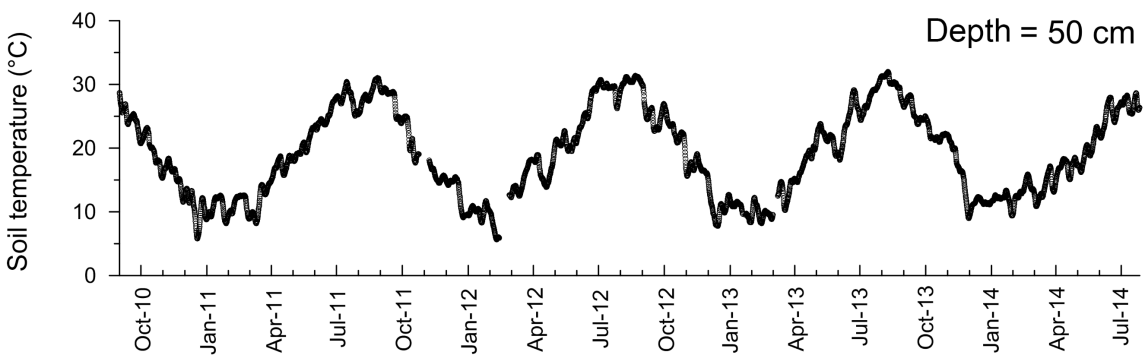

Figure 7. Evolution of temperature, $T$, recorded by the physical model of lysimeter: (a) soil temperature at depth of $5 \mathrm{~cm}$; (b) soil temperature at depth of $15 \mathrm{~cm}$; (c) soil temperature at depth of $50 \mathrm{~cm}$.

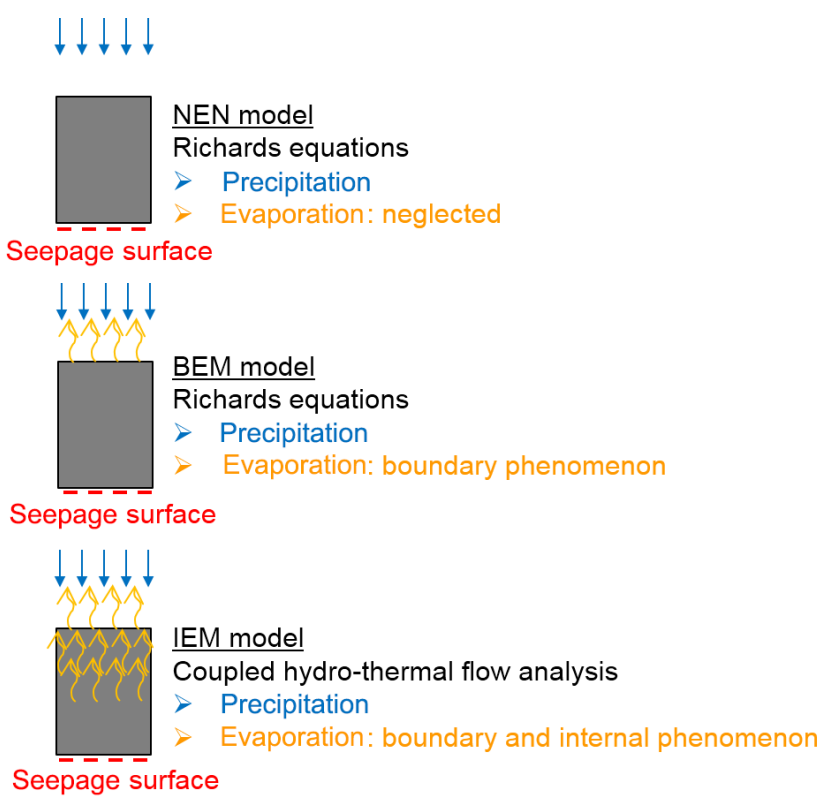

Figure 8. Model schemes adopted for early warning predictions.

result into 1-D (downward and upward, respectively) flow conditions throughout the cover and that transition periods associate with rotation of flow vectors;
- The rigidity of the domain. Neglecting the effects of deformational processes induced by suction changes is suggested by the stiff volumetric response observed under-swelling-reloading paths, which should speed up re-equilibrium processes so that hydraulic response is unaffected by the consolidation delay.

- Modelling of hourly rainfall as hydraulic boundary conditions at the top surface of the domain. There a water flux condition equal to rainfall intensity is maintained if pore water pressure at the top is less than zero (a positive value would indicate ponding formation). Otherwise, a null pore water pressure condition is assumed and maintained if the computed entering water flux is less than rainfall intensity. In contrast, entering flux is again applied at the rainfall intensity.

- Surface seepage is applied at the bottom boundary. This condition corresponds to the hypothesis that the bedrock the volcanic layer rests on is intensely fractured and that the fractures are filled only by air (Reder et al., 2017).

The more comprehensive approach adopted couples the water balance equation with the heat balance equation and thermodynamic equilibrium (Wilson et al., 1994) and is applied using the Vadose/W code (Geo-Slope, 2008). 
The water balance equation is expressed as

$$
\begin{aligned}
\frac{1}{\rho_{\mathrm{w}} g} \frac{\partial\left(u_{\mathrm{a}}-u_{\mathrm{w}}\right)}{\partial t} & =\frac{1}{\rho_{\mathrm{w}} g m_{2}^{\mathrm{W}}}\left[\frac{\partial}{\partial z}\left(k_{\mathrm{w}}+\frac{k_{\mathrm{w}}}{\rho_{\mathrm{w}} g} \frac{\partial\left(u_{\mathrm{a}}-u_{\mathrm{W}}\right)}{\partial z}\right)\right. \\
& \left.+\left(\frac{P_{\mathrm{a}}+u_{\mathrm{v}}}{P_{\mathrm{a}} \rho_{\mathrm{w}}}\right) \frac{\partial}{\partial z}\left(D_{\mathrm{v}} \frac{\partial u_{\mathrm{v}}}{\partial z}\right)\right],
\end{aligned}
$$

where $u_{\mathrm{w}}\left(\mathrm{ML}^{-1} \mathrm{~T}^{-2}\right)$ is liquid pore water pressure, $u_{\mathrm{a}}$ $\left(\mathrm{ML}^{-1} \mathrm{~T}^{-2}\right)$ is pore air pressure, $u_{\mathrm{v}}\left(\mathrm{ML}^{-1} \mathrm{~T}^{-2}\right)$ is the partial pressure of vapour pore water, $m_{2}^{\mathrm{w}}\left(\mathrm{L} \mathrm{T}^{2} \mathrm{M}^{-1}\right)$ is the slope of soil-water characteristic curve (SWCC), $P_{\mathrm{a}}$ $\left(\mathrm{ML}^{-1} \mathrm{~T}^{-2}\right)$ is total atmospheric pressure, $k_{\mathrm{W}}\left(\mathrm{L} \mathrm{T}^{-1}\right)$ is the hydraulic conductivity function $(\mathrm{HCF}), D_{\mathrm{v}}(\mathrm{T})$ is the function of vapour diffusivity through the soil, $\rho_{\mathrm{w}}\left(\mathrm{ML}^{-3}\right)$ is the liquid water density and $g\left(\mathrm{~L} \mathrm{~T}^{-2}\right)$ is the gravitational acceleration.

In comparison with the traditional form of water balance equation, describing the flow of liquid water through porous media, Eq. (1) contains an additional term (the second one in square brackets) considering possible changes in the water phase.

The heat balance equation is expressed as

$C_{\mathrm{h}} \frac{\partial T}{\partial t}=\frac{\partial}{\partial z}\left(\lambda \frac{\partial T}{\partial z}\right)-L_{\mathrm{v}}\left(\frac{P_{\mathrm{a}}+u_{\mathrm{v}}}{P_{\mathrm{a}}}\right) \frac{\partial}{\partial z}\left(D_{\mathrm{v}} \frac{\partial u_{\mathrm{v}}}{\partial z}\right)$,

where $T(\Theta)$ is the soil temperature, $C_{\mathrm{h}}\left(\mathrm{ML}^{-1} \mathrm{~T}^{-2} \Theta^{-1}\right)$ is the function of volumetric specific heat, $\lambda\left(\mathrm{M} \mathrm{L} \mathrm{T}^{-3} \Theta^{-1}\right)$ is the function of thermal conductivity and $L_{\mathrm{v}}\left(\mathrm{L}^{2} \mathrm{~T}^{-2}\right)$ is the latent heat of water vaporization.

In this equation, the last term accounts for the amount of energy spent on water vaporization and represents the coupling with the water balance equation.

Thermodynamic equilibrium is expressed as

$u_{\mathrm{v}}=u_{\mathrm{v}_{0}} \exp \left(\frac{\left(u_{\mathrm{a}}-u_{\mathrm{w}}\right) M_{\mathrm{w}} g}{R T}\right)$,

where $u_{\mathrm{v}_{0}}\left(\mathrm{ML}^{-1} \mathrm{~T}^{-2}\right)$ is the saturated partial pressure of pore vapour, $M_{\mathrm{W}}\left(\mathrm{M} \mathrm{N}^{-1}\right)$ is the water molecular weight and $R\left(\mathrm{M} \mathrm{L}^{2} \mathrm{~T}^{-2} \mathrm{~N}^{-1} \Theta^{-1}\right)$ is the ideal gas constant.

The described model requires the following boundary conditions:

- Soil suction $\left(u_{\mathrm{a}}-u_{\mathrm{w}}\right)_{\mathrm{s}}$ or, alternatively, liquid water flux $\left(v_{\mathrm{w}}\right)_{\mathrm{S}}$ at the top boundary. Infiltrating precipitation was reproduced as already described in this section, and AE was reproduced according to the FAO approach described in what follows; $u_{\mathrm{a}}$ is assumed to be the same as the atmospheric pressure;

- Vapour pressure $\left(u_{\mathrm{v}}\right)_{\mathrm{s}}$ or, alternatively, vapour water flux $\left(v_{\mathrm{v}}\right)_{\mathrm{s}}$. The boundary value problem was addressed by quantifying the former from air relative humidity $\mathrm{RH}$ and air temperature $T_{\mathrm{a}}$ records. $\mathrm{RH}$ provides the ratio $\left(u_{\mathrm{V}}\right)_{\mathrm{S}} /\left(u_{\mathrm{v}_{0}}\right)_{\mathrm{S}}$, while $T_{\mathrm{a}}$ provides the partial pressure of the vapour phase in saturated conditions $\left(u_{\mathrm{v}_{0}}\right)_{\mathrm{s}}$ using the Tetens equation (Tetens, 1930).
- Temperature $T_{\mathrm{s}}$ is assumed to equal air temperature $T_{\mathrm{a}}$ measured $2 \mathrm{~m}$ above the surface of the ground, in line with the approach followed by Wilson et al. (1997).

Maximum values of $\mathrm{AE}$ correspond to atmospheric demand PE; however, soil moisture conditions AE can be reduced according to the falling law proposed by Wilson et al. (1997),

$\mathrm{AE}=k \mathrm{PE}$,

where $k$ is equal to

$k=\frac{\exp \left(\frac{\left(u_{\mathrm{a}}-u_{\mathrm{w}}\right)_{\mathrm{s}} M_{\mathrm{w}} g}{R T_{\mathrm{s}}}\right)-\mathrm{RH}}{1-\mathrm{RH}}$,

and the PE expression of the FAO approach (Allen et al., 1998),

$\mathrm{PE}=k_{\text {crop }}\left[\frac{0.408 \Gamma\left(R_{\mathrm{n}}-G\right)+\eta \frac{900}{T_{\mathrm{a}}+273} u_{2 \mathrm{~m}}\left(u_{\mathrm{v}_{0}}^{\mathrm{air}}-u_{\mathrm{v}}^{\mathrm{air}}\right)}{\Gamma+\eta\left(1+0.34 u_{2 \mathrm{~m}}\right)}\right]$,

where $k_{\text {crop }}(-)$ is the crop coefficient, $\Gamma\left(\mathrm{ML}^{-1} \mathrm{~T}^{-2} \Theta^{-1}\right)$ is the slope of the vapour pressure curve, $\eta\left(\mathrm{ML}^{-1} \mathrm{~T}^{-2} \Theta^{-1}\right)$ is the psychrometric constant, $R_{\mathrm{n}}\left(\mathrm{M} \mathrm{L}^{-2} \mathrm{~T}^{-3}\right)$ is the net radiation flux, $G\left(\mathrm{ML}^{-2} \mathrm{~T}^{-3}\right)$ is the soil heat flux and $u_{2 \mathrm{~m}}$ $\left(\mathrm{L} \mathrm{T}^{-1}\right)$ is the wind speed measured $2 \mathrm{~m}$ above the surface of the ground. The FAO approach takes the various crop conditions into account thanks to the $k_{\text {crop }}$ coefficient that transforms the potential evaporation of the reference surface (in square brackets) into PE in relation to the actual surface (a bare surface in the case at hand). This coefficient was quantified in Rianna et al. (2014b) as $k_{\text {crop }}=1.15$ by using PE measurements provided by the physical model. This is consistent with the literature indications (Allen et al., 1998, 2005).

It is important to highlight that the model described above incorporates evaporation as both a superficial and an internal phenomenon, suited to reproducing the possible deepening of the water-state-change surface over dry and hot periods. Hereafter, this model will be referred to as the "internal evaporation model", or IEM. Such modelling has been successfully adopted for investigating different issues: e.g. embankment stability analysis (Gitirana Jr., 2005; Briggs et al., 2016), soil-structure interaction (Al Qadad et al., 2012) and generic soil-water budget (Cui et al., 2005).

Richards' equation constitutes a simplified version of the described model. It consists of the water balance Eq. (1) for liquid water, thus removing the vapour flow term, and Eq. (4), specified by Eqs. (5) and (6). This isothermal approach only takes into account changes in atmospheric temperature through Eq. (5), where it is assumed that $T_{\mathrm{s}}=T_{\mathrm{a}}$ (an approach called "isothermal model with atmospheric coupling" by Fredlund et al., 2012). The model takes only evaporation into account as a boundary phenomenon, which occurs only at the top boundary, with no possibility of a downward shift of the water-state-change surface. Hereafter, this model will be referred to as the "boundary evaporation model", or BEM. 

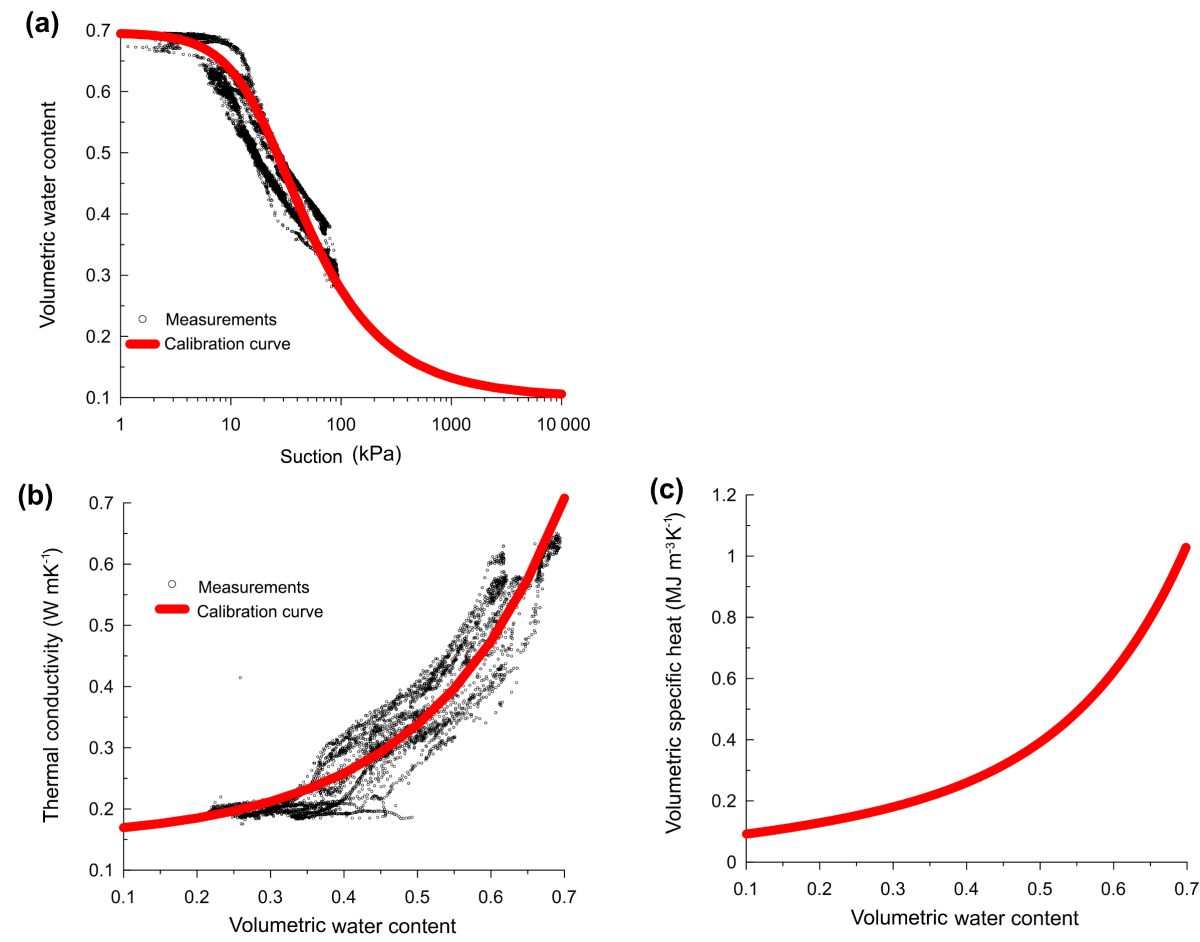

Figure 9. Calibration of model parameters: (a) experimental point at the depths of 15 and $70 \mathrm{~cm}$ versus fitting water retention curve; (b) experimental point versus fitting thermal conductivity function; (c) volumetric specific heat function.

A further simplification often adopted in single applications (Pagano et al., 2010) or in a number of codes developed to estimate slope stability conditions over extensive sloping territory (Iverson, 2000; Montgomery and Dietrich, 1994; Baum et al., 2008) corresponds to the latter approach (Richards equations) applied without accounting for evaporation. This model will subsequently be referred to as the "no evaporation model", or NEM.

All the simulations were performed using an input-output hourly time step; moreover, the adaptive time stepping scheme proposed by Milly (1982) was adopted for inner time step.

\subsection{Calibration and model parameters}

The IEM is a generalization of the BEM or NEM. Hence, the soil properties and parameters IEM contains also pertain to BEM and NEM. Calibration refers to both thermal (soil thermal conductivity and volumetric specific heat) and hydraulic properties (the soil-water retention curve and the hydraulic conductivity function), the latter being common to the other two approaches.

Parameters were calibrated from the results provided by the physical model over the first 2 years. The results collected over the subsequent 2 years were adopted to validate the calibration.

Some of the soil properties were quantified directly from measurements. This is the case of the SWCC, which was obtained as the best-fit function of (water content)-(suction) points recorded by TDRs and jet-fill tensiometers (Fig. 9a). The SWCC adopted interpolates experimental data available up to suction values of around $90 \mathrm{kPa}$ and extrapolates them to much higher suction levels, adopting as asymptote the lowest volumetric water content measured locally by TDRs.

This is also the case of the thermal conductivity function $(\lambda)$, which was derived as best-fit function (Fig. 9b) of (water content)-(thermal conductivity) points recorded at all depths. Thermal conductivity values were obtained using heat dissipation probes, referring to the relationship relating probe energization $q$ to $q$-induced temperature changes $\Delta T$ (Shiozawa and Campbell, 1990):

$q=4 \pi \ln (\Delta T) \lambda$,

which contains $\lambda$ as a single unknown.

The volumetric specific heat $C_{\mathrm{h}}$ and hydraulic conductivity functions, in contrast, were quantified following articulated and novel interpretation procedures of experimental data based on back analysis.

$C_{\mathrm{h}}$ was determined by solving the heat equation at sublayers with the thicknesses demarcated by a triplet of temperature measurement points. By assuming that the energy spent for evaporation within each sublayer is negligible, and $\lambda$ is constant at the mean value assumed throughout the sublayer $(\bar{\lambda})$, the heat equation may be rewritten as 
(a)

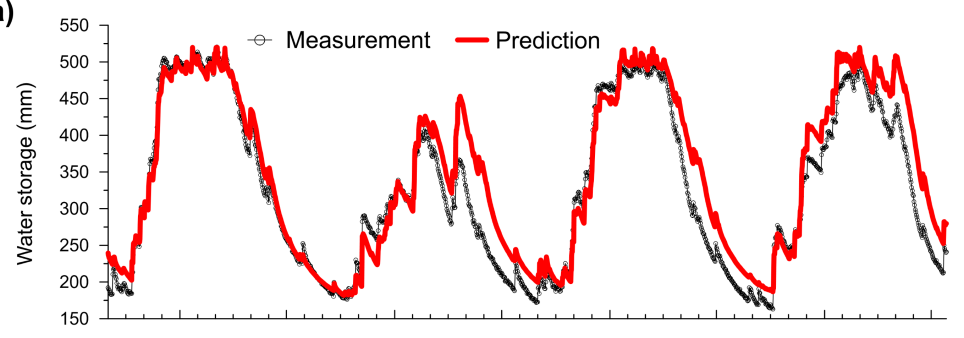

(b)

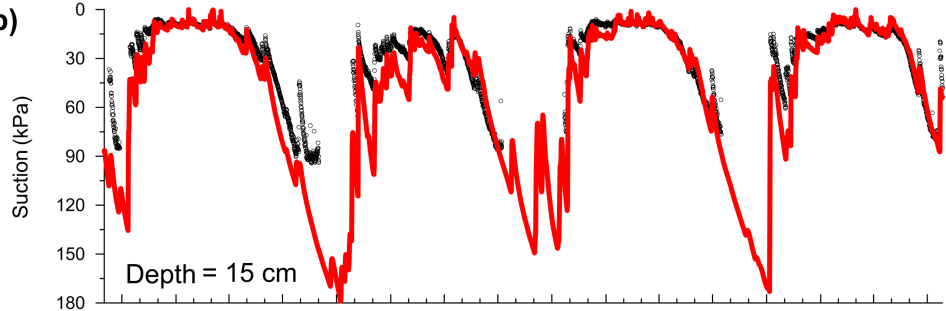

(c)

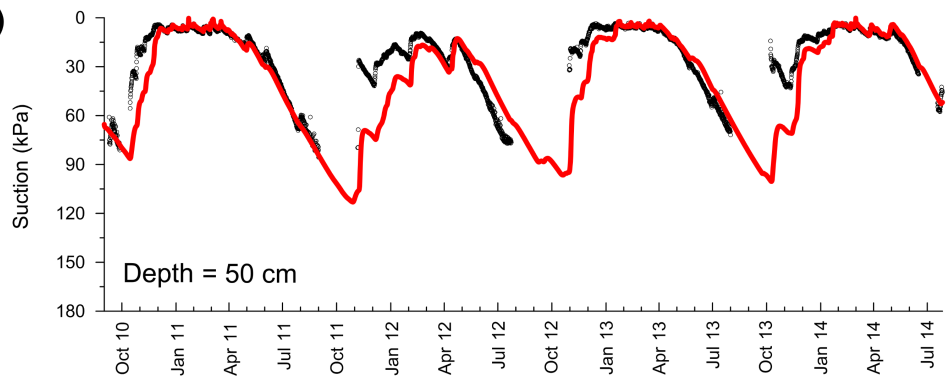

Figure 10. Back analysis of the observed layer hydrological behaviour by the IEM: (a) measured versus IEM-predicted water storage (WS); (b) measured versus IEM-predicted suction at depth of $15 \mathrm{~cm}$; (c) measured versus IEM-predicted suction at depth of $50 \mathrm{~cm}$.

$$
\frac{\partial T}{\partial t}=\frac{\bar{\lambda}}{C_{\mathrm{h}}} \frac{\partial^{2} T}{\partial z^{2}} .
$$

This equation was solved by regarding the two external temperature measurements of the sublayer as boundary conditions and considering internal measurement $T^{*}$, a reference for calibrating $\bar{\lambda} / C_{\mathrm{h}}$, as the value that gives the best fit of the evolution of $T^{*}$ over the first 2 years of observations. Preliminary knowledge of $\bar{\lambda}$ then makes it possible to obtain $C_{\mathrm{h}}$ (Fig. 9c).

Having established SWCC and thermal properties, the HCF was calibrated via a back analysis of the hydrological behaviour of the layer observed over the first 2 years. A domain of the same thickness $(0.75 \mathrm{~m})$ as the layer placed in the physical model was assumed to be subject to boundary conditions at the top surface reproducing the recorded atmospheric variables. Figure 10 shows that the agreement between measurements and predictions obtained from the back analysis is satisfactory both in terms of water storage (Fig. 10a) and suction (Fig. 10b). Predictions match observations not only within the calibration range but also outside it (validation phase). Figure 11 plots the hydraulic conductivity function resulting from back analysis. The hydraulic conductivity of the material drops by 3 orders of magnitude (from $10^{-6}$ to $10^{-9} \mathrm{~m} \mathrm{~s}^{-1}$ ), with suction increasing from 0 to $100 \mathrm{kPa}$.

Table 1 lists parameter values obtained from calibration based on experimental results provided by the physical model. Hydraulic conductivity function and water retention curve are fully consistent with those indicated for the same soil type by Nicotera et al. (2010) and Pirone et al. (2015b). Thermal parameters for these soils are instead quantified in this work for the first time.

Upon completion of parameter calibration, thermal functions $\lambda$ and $C_{\mathrm{h}}$ were further validated by checking their ability to reproduce the observed thermal behaviour under the effects of the recorded atmospheric variables. Figure 12 shows that the model yields temperature predictions fully consistent with temperature measurements at all depths over the 4 years of available observations.

As stated previously, IEM calibration also implies automatic BEM and NEM calibration. Figure $13 \mathrm{a}$ and $\mathrm{b}$ add to the plots of Fig. 10 the predictions of the BEM in terms of WS and suction. It can be observed that even the approach incorporating evaporation as only a boundary phenomenon performs well in reproducing the recorded hydrological pattern. The predictions yielded by the two approaches (IEM and BEM) match during winter and early spring when ac- 
Table 1. Soil functions and estimated parameters for investigated soil.

\begin{tabular}{llll}
\hline Soil-water characteristic curve & Hydraulic conductivity function & $\begin{array}{l}\text { Volumetric specific heat } \\
\text { function }\end{array}$ & $\begin{array}{l}\text { Thermal conductivity } \\
\text { function }\end{array}$ \\
\hline$\frac{\theta-\theta_{\mathrm{r}}}{\theta_{\mathrm{s}}-\theta_{\mathrm{r}}}=S_{\mathrm{e}}=\left[1+\left(\alpha\left|u_{\mathrm{a}}-u_{\mathrm{\textrm {W }}}\right|\right)^{n}\right]^{-\left(1-\frac{1}{n}\right)}$ & $K_{\mathrm{W}}=K_{\mathrm{Ws}}\left(S_{\mathrm{e}}\right)^{l}\left\{1-\left[1-\left(S_{\mathrm{e}}\right)^{\frac{1}{m}}\right]^{m}\right\}^{2}$ & $C_{\mathrm{h}}=C_{\mathrm{h}_{0}}+\alpha_{0} \exp \left(b_{0} \theta\right)$ & $\lambda=\lambda_{1}+\alpha_{1} \exp \left(b_{1} \theta\right)$ \\
$($ van Genuchten, 1980) & $($ Mualem, 1976; van Genuchten, 1980) & $C_{\mathrm{h}_{0}, \alpha_{0}, b_{0} \text { fitting parameters }}$ & $\lambda_{1}, \alpha_{1}, b_{1}$ fitting parameters \\
$S_{\mathrm{e}}$ is effective saturation degree & $K_{\mathrm{ws}}$ is saturated hydraulic conductivity & $C_{\mathrm{h}_{0}}=0.055 \mathrm{MJ} \mathrm{m}^{-3} \mathrm{~K}$ & $\lambda_{1}=0.148 \mathrm{~W} \mathrm{~m} \mathrm{~K} \mathrm{~K}^{-1}$ \\
$\theta_{\mathrm{S}}$ is residual water content $=0.696$ & $=1 \times 10^{-6} \mathrm{~m} \mathrm{~s}^{-1}$ & $\alpha_{0}=0.025 \mathrm{MJ} \mathrm{m}^{-3} \mathrm{~K}$ & $\alpha_{1}=0.013 \mathrm{~W} \mathrm{~m} \mathrm{~K}^{-1} \mathrm{~K}$ \\
$\theta_{\mathrm{r}}$ is the saturated water content $=0.100$ & $l$ is the fitting parameter $=-0.5$ & $b_{0}=5.252$ & $b_{1}=5.406$ \\
$\alpha$ is the inverse of air entry suction $=0.0471 / \mathrm{kPa}$ & & & \\
$n$ is the fitting parameter $=1.760$ & & & \\
\hline
\end{tabular}

Table 2. Nash-Sutcliffe, Kling-Gupta and coefficient of determination assessed for proxy variables (WS, suction and temperature at different depths) considering all periods, only calibration periods (first and second hydrological year) and only validation periods (third and fourth hydrological year).

\begin{tabular}{|c|c|c|c|c|c|c|c|c|c|}
\hline & \multicolumn{3}{|c|}{ Nash-Sutcliffe } & \multicolumn{3}{|c|}{ Kling-Gupta } & \multicolumn{3}{|c|}{$\begin{array}{l}\text { Coefficient of } \\
\text { determination }\end{array}$} \\
\hline & All & $\mathrm{Cal}$ & Val & All & $\mathrm{Cal}$ & Val & All & Cal & Val \\
\hline WS & 0.89 & 0.91 & 0.88 & 0.93 & 0.94 & 0.92 & 0.93 & 0.93 & 0.93 \\
\hline Suction $15 \mathrm{~cm}$ & 0.54 & 0.43 & 0.68 & 0.58 & 0.53 & 0.72 & 0.85 & 0.86 & 0.83 \\
\hline Suction $30 \mathrm{~cm}$ & 0.57 & 0.55 & 0.55 & 0.72 & 0.71 & 0.73 & 0.74 & 0.75 & 0.69 \\
\hline Suction $50 \mathrm{~cm}$ & 0.36 & 0.45 & 0.04 & 0.65 & 0.71 & 0.50 & 0.61 & 0.62 & 0.54 \\
\hline Suction $70 \mathrm{~cm}$ & 0.44 & 0.39 & 0.39 & 0.68 & 0.68 & 0.65 & 0.63 & 0.60 & 0.62 \\
\hline Temperature $5 \mathrm{~cm}$ & 0.75 & 0.74 & 0.76 & 0.75 & 0.73 & 0.77 & 0.97 & 0.97 & 0.97 \\
\hline Temperature $15 \mathrm{~cm}$ & 0.82 & 0.82 & 0.83 & 0.80 & 0.80 & 0.81 & 0.98 & 0.97 & 0.98 \\
\hline Temperature $30 \mathrm{~cm}$ & 0.92 & 0.91 & 0.93 & 0.83 & 0.81 & 0.86 & 0.97 & 0.98 & 0.97 \\
\hline Temperature $50 \mathrm{~cm}$ & 0.93 & 0.93 & 0.93 & 0.90 & 0.89 & 0.91 & 0.95 & 0.95 & 0.94 \\
\hline Temperature $70 \mathrm{~cm}$ & 0.96 & 0.96 & 0.96 & 0.93 & 0.93 & 0.93 & 0.96 & 0.97 & 0.96 \\
\hline
\end{tabular}

tual evaporation attains potential levels. In this case, in fact, evaporation really occurs as a boundary phenomenon. The predictions depart instead during late spring, summer and autumn, when internal evaporation phenomena take place or the effects of their previous occurrence are felt. During these periods, IEM predictions reproduce observations better than $\mathrm{BEM}$ ones, as the latter either overestimates water storage or underestimates suction.

A synthetic overview about the capability of calibrated approach in reproducing observed values is reported in Table 2. It reports an evaluation of goodness of fit for WS, suction and temperature obtained by using Nash-Sutcliffe (Nash and Sutcliffe, 1970), Kling-Gupta (Gupta et al., 2009) and the coefficient of determination. Advantages and constraints of such approaches are largely investigated in literature (Krause et al., 2005; Bennet et al., 2013). The results are differentiated considering calibration and validation periods both separately and jointly. In general, satisfying results are achieved for WS and temperature, where over all periods the three indices never fall below 0.74 (over 0.88 for WS); however, worse performances arise considering suction, especially adopting Nash-Sutcliffe approach. These discrepancies are likely due to disregarding hydraulic hysteretic dy-

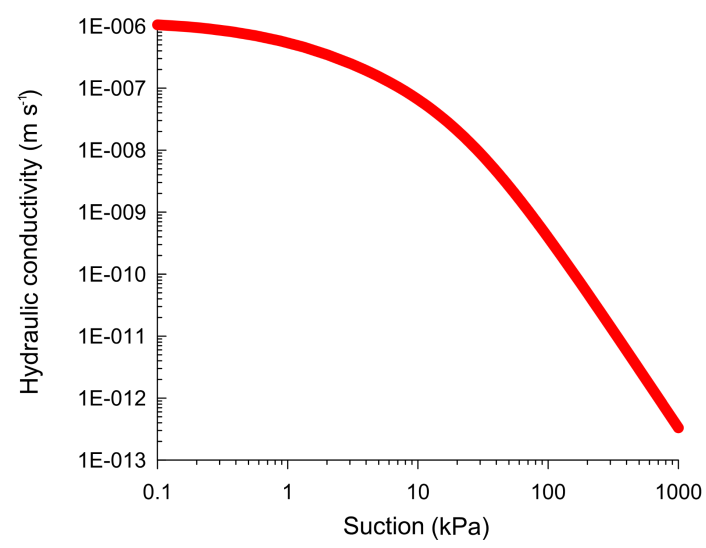

Figure 11. The hydraulic conductivity function obtained from the IEM back analysis of the hydrological behaviour.

namics using a unique SWCC aimed to catch the average behaviour of soil in wetting and drying paths. As shown by Rianna et al. (2017), this simplification may sometimes result in an increased time lag of suction-drop response to precipitation, especially when the initial state point falls near the main drying curve. 


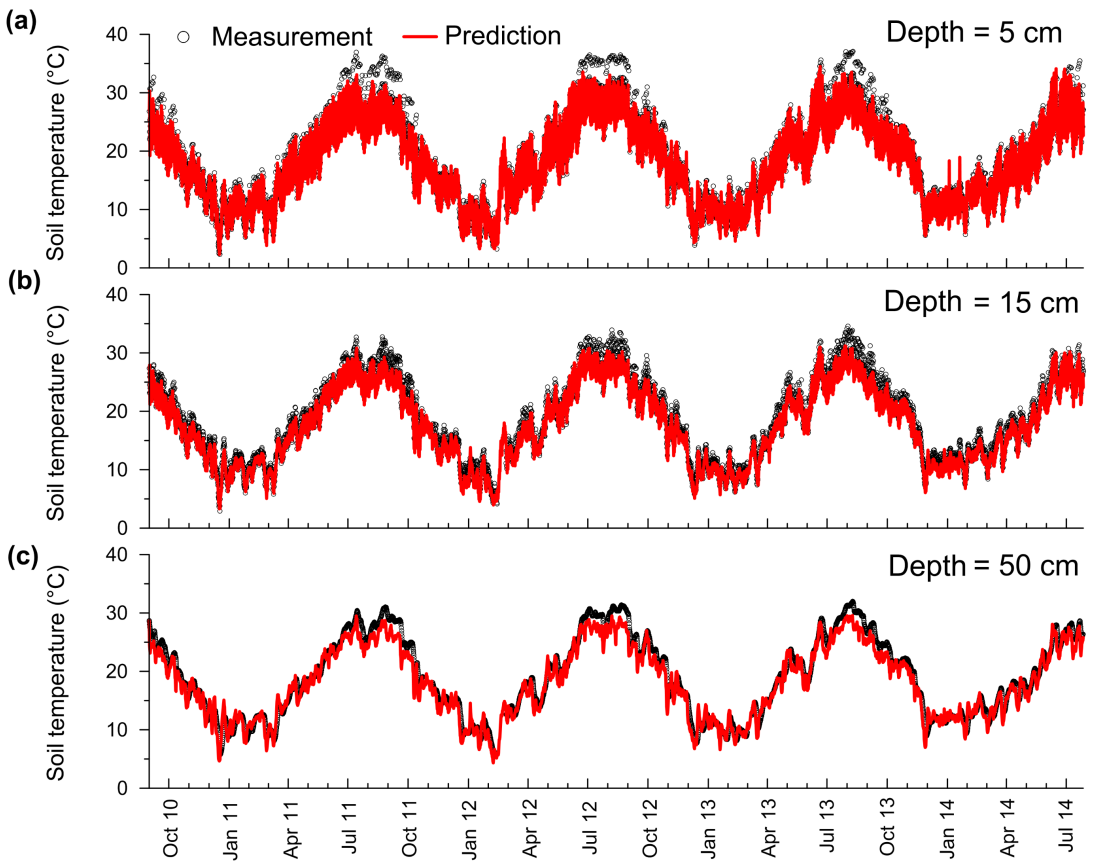

Figure 12. Measured versus IEM-predicted temperature $(T)$ evolutions at three different depths indicated.

\section{Results and discussion}

\subsection{Patterns of AE predictions under simplified PE evolutions}

In order to further investigate differences in the predictions yielded by the IEM and BEM, the model responses were compared under much simpler boundary conditions than those considered in reproducing the behaviour of the physical model (Fig. 13). With the models calibrated as described above, the two approaches incorporating evaporation were compared in a numerical experiment. They were used to predict actual evaporative fluxes they return under the effects of the same virtual PE flux applied at the top boundary. PE is supposed to act with an intensity of $4.5 \mathrm{~mm}$ per day and constant over 60 days. Such value represents the mean evaporative atmospheric demand estimated through available weather forcing for summer during the physical model monitoring. The response of the two models was plotted in terms of both AE evolution (Fig. 14a) and hydraulic conductivity evolution at the top surface (Fig. 14b). The AE values yielded by the two models coincide when $\mathrm{AE}$ is equal to $\mathrm{PE}$, in line with what was illustrated above in discussing the trends in Fig. 13. There is a time, under such forcing, when AE departs from $\mathrm{PE}$ in the two predictions. It corresponds to the moment when upward water fluxes are no longer able to fully supply the top surface with the water amount satisfying the hypothesized atmospheric demand for evaporation ( $4.5 \mathrm{~mm}$ per day). After this time, the two AE predictions also diverge and follow a substantially different evolution. A drop in AE typifies the BEM response. This is due to the fact that the model generates vapour only from liquid water reaching the top surface. When AE diverges from PE, a shallow thin zone placed below the top surface desaturates more than the interior. With increasing suction, hydraulic conductivity decreases and hydraulic gradients increase, with the former having a greater effect on flow reduction (Fig. 14b). In turn, this reduction slows the upward water flux, so that water losses induced by the PE action in this shallow thin zone are no longer compensated by water supplied from the interior. In this way, under the effect of desaturation dynamics the thin, shallow zone shortly reaches the residual water content and very low hydraulic conductivity values. At this point, the upward water flux from the interior is almost totally inhibited, in a sort of barrier effect exerted by the shallow thin zone, implying the vanishing of AE. This barrier effect inhibits further desaturation processes inside the domain. Consistently, suction attains very high values within the cap zone, remaining at low levels inside the domain.

In contrast, the IEM is suited to reproduce the occurrence of internal evaporation as soon as the zone placed below the top surface desaturates more than the interior at the time of $\mathrm{PE}-\mathrm{AE}$ divergence. Vapour starts to generate within the interior of the domain other than at the boundary, in an automatic and progressive deepening of the water phase-change surface. Interior vapour forms and migrates upward at a rate that is now regulated by vapour conductivity. This latter, unlike with hydraulic conductivity, progressively increases as the degree of saturation decreases, so that vapour migration takes place at a rate that maintains $\mathrm{AE}$ at significant levels. It 


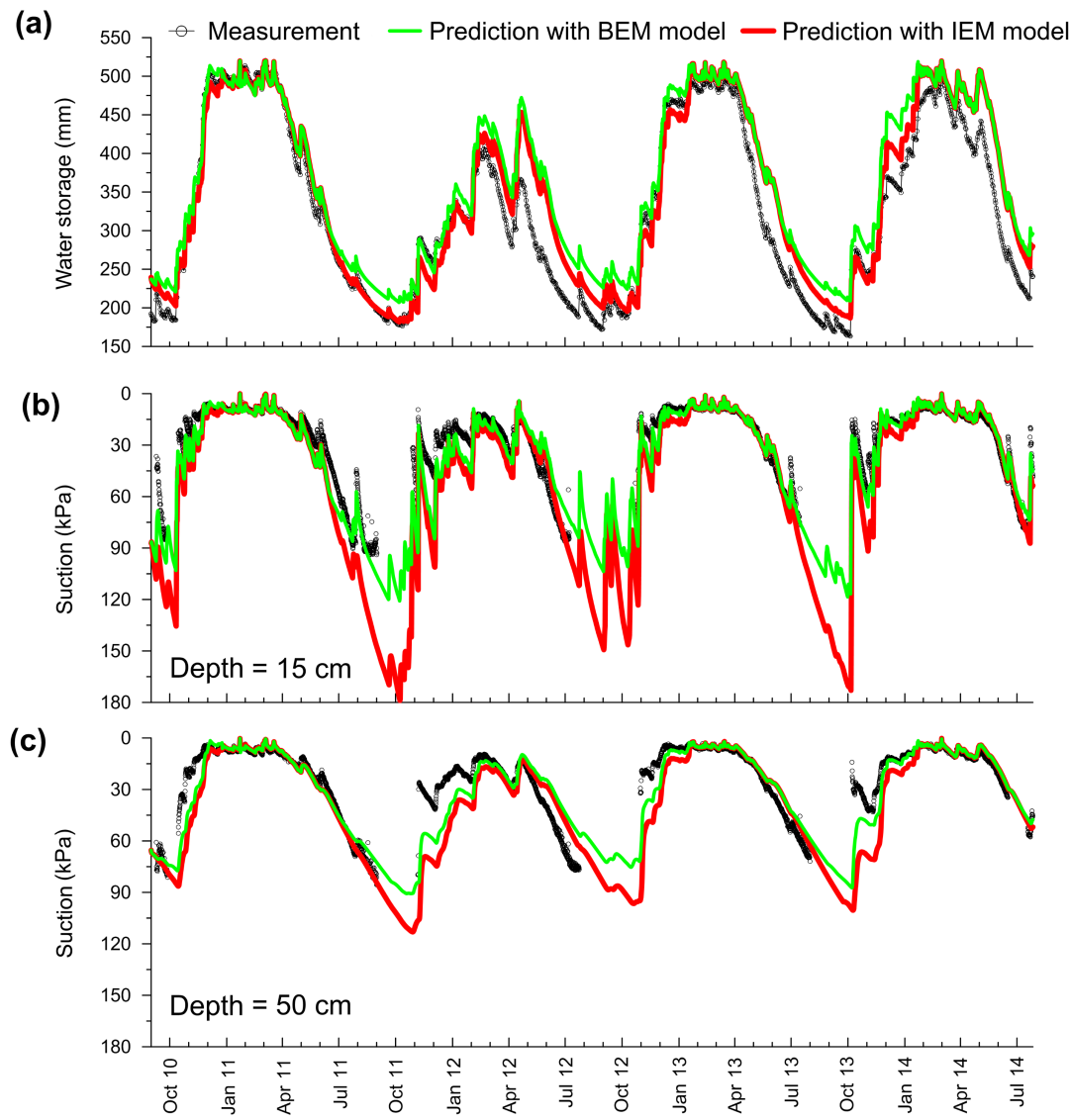

Figure 13. Comparison between IEM-predicted, BEM-predicted and observed hydrological behaviour: (a) comparisons in terms of water storage (WS) evolutions; (b) comparisons in terms of suction evolutions at depth of $15 \mathrm{~cm}$; (c) comparisons in terms of suction evolutions at depth of $50 \mathrm{~cm}$.

follows that $\mathrm{AE}$ reduction is gradual in the IEM predictions as it is effectively supplied by the interior vapour generation. Furthermore, as internal vapour approaches the top surface, it also reduces suction levels there as a consequence of thermodynamic equilibrium (Eq. 3). This contributes to maintaining hydraulic conductivity at levels much higher than those associated with the BEM prediction. Boundary evaporation also occurs at a consistently higher rate, or, in other words, the formation of any barrier effect is prevented. Compared with BEM prediction, in the IEM prediction, vapour migration produces suction levels (Fig. 15c) that are lower near the top surface and higher within the domain interior when desaturation processes are more significant.

It is worth highlighting that the high suction values predicted by the above numerical analyses at the top surface are not only theoretically based (see for example Wilson et al., 1994, 1997), but they could be experienced by silty pyroclastic covers during the hot, dry season. For instance, Pagano et al. (2014) measured suction at the layer topsoil by heat dissipation probes up to $10000 \mathrm{kPa}$. Both numerical and experimental results hence indicate that during the hot, dry season very high topsoil suction merge with moderately lower interior suction values.

\subsection{Interpretative analyses of the Nocera Inferiore 2005 landslide}

\subsubsection{Preliminary assumptions and considerations}

In order to investigate the potential of the IEM and BEM in interpreting the $2005 \mathrm{NIL}$ and establishing their reliability as predictive tools in early warning systems, the cover thickness $(2 \mathrm{~m})$ in the zone where the landslide triggered was analysed by assuming one-dimensional water fluxes.

The reliability of the one-dimensional assumption has already been discussed at the beginning of Sect. 2.3. The analyses were carried out according to the hypotheses formulated in Sect. 2.3, quantifying the model parameters from experimental data provided by the lysimeter (Table 1). As mentioned in the Introduction, hydraulic retention properties estimated from laboratory and lysimeter experiments were compared with those obtained by field monitoring (Pirone et al., 2016). Consistency of results encouraged in using lysimeter- 


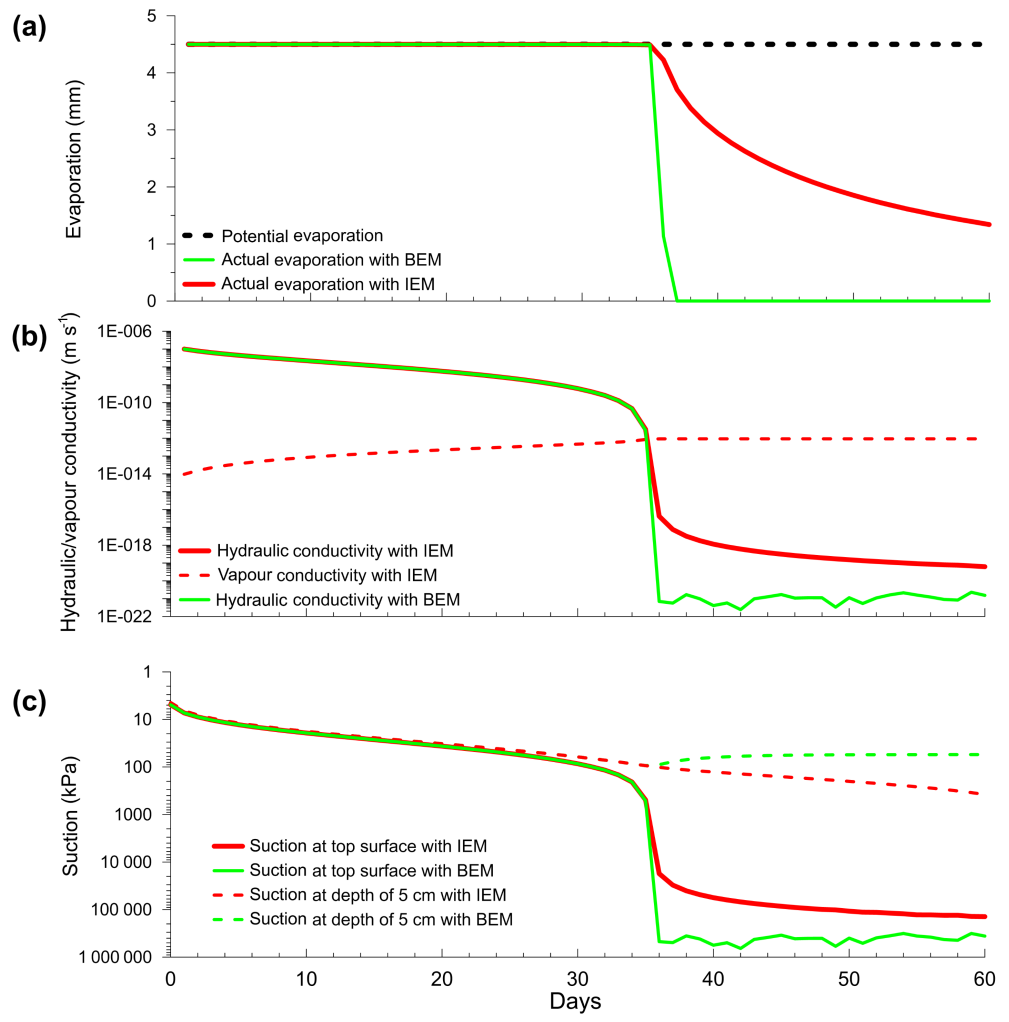

Figure 14. Comparison of variables yielded by IEM and BEM predictions under $P E=4.5$ mm day $^{-1}$ : (a) comparisons between actual evaporative fluxes (AE); (b) comparisons between hydraulic conductivities at the top surface and evolution of vapour conductivity at the top surface; (c) comparisons between evolutions of suction at the top surface and at depth of $5 \mathrm{~cm}$.

based quantification of all parameters for field predictions. The "specimen" adopted in the present study to quantify parameters $\left(1 \mathrm{~m}^{3}\right)$ is 5 orders of magnitude larger than those typically adopted $\left(3 \times 10^{-5} \mathrm{~m}^{3}\right)$. Hydraulic conductivity is hence measured at a mesoscale, a condition that should be quite representative of field conditions.

The chain of events inducing a rainfall-induced landslide in a silty volcanic sloping cover can schematically be illustrated in subsequent or parallel stages as follows (Pagano et al., 2008a): (1) a generalized suction drop, (2) a suctioninduced strength reduction, (3) trigger of instability due to local peculiarities, internal or external to the slope and (4) propagation of local trigger throughout the cover. The approach followed to interpret the $2005 \mathrm{NIL}$ in view of structuring an early warning prediction consists of limiting the analysis to the characterization of suction levels predisposed to instability (stage 1) rather than carrying out all steps towards an assessment of the slope safety factor. Converting suction distribution into prediction of slope safety factor would involve a slope stability analysis. The latter implies the complex issue of characterizing soil strength and the strength action exerted by roots, which is very difficult to quantify. In addition, the uncertainty in a local trigger cause would intrinsically make difficult carrying out stability analyses.
As root strength action also founds on suction levels (rootsoil bonds are mostly promoted by suction), the approach followed limits to predict the suction-dependent predisposing stage by physically based approaches. WS may also be used in place of suction, as it is a function of suction distribution. It has already been adopted as proxy of slope safety conditions in previous early warning applications, starting from the well-known Seattle implementation (Baum and Godt, 2010).

The evolution of meteorological variables recorded at the landslide site over the entire 10 years (Fig. 3), including the time of the landslide, was then converted into the evolution of WS and suction in the middle of the domain analysed (to a depth of $1 \mathrm{~m}$ ) via the IEM and BEM predictions. With the aim of possibly using these models for physically based early predictions, these variables were considered as proxies from which different alert thresholds can be defined.

\subsubsection{Results}

Figure 15a plots the WS evolutions yielded by the IEM and BEM analyses. Both are able to reproduce the typical WS patterns that develop over a hydrological year, as shown by the experimental data provided by the physical model: WS fluctuates during the year, increasing during autumn, 
(a)

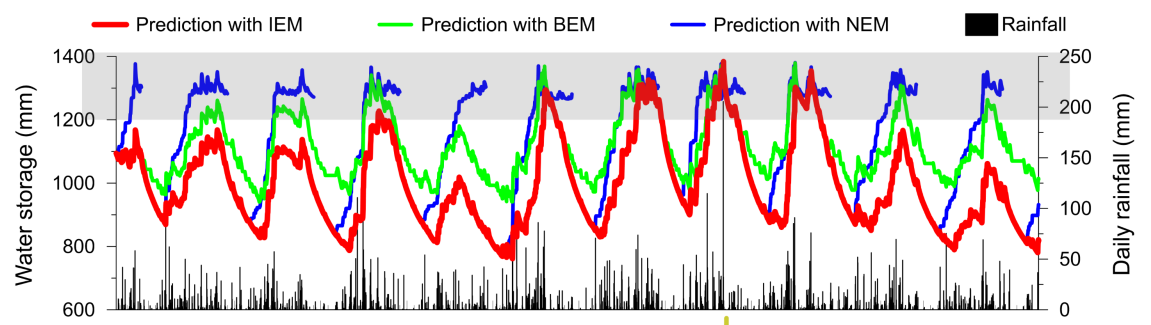

(b)

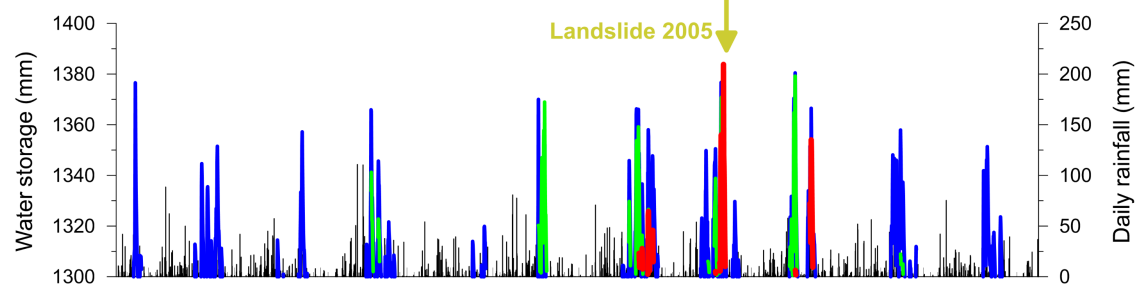

(c)

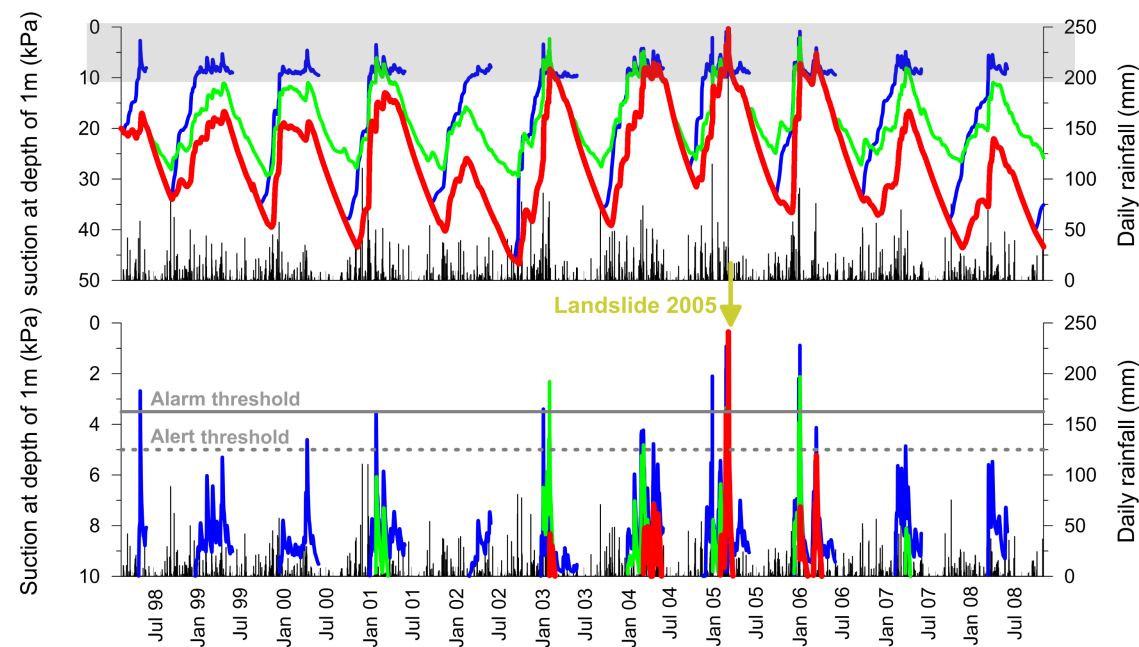

Figure 15. NEM, BEM and IEM predictions of the hydrological behaviour evolution for the layer involved in the 2005NIL: (a) prediction within the WS full range; (b) prediction for WS levels higher than $1300 \mathrm{~mm}$; (c) prediction within the suction full range; (d) prediction for suction levels lower than $10 \mathrm{kPa}$.

winter and early spring due to precipitation and reducing during late spring and summer due to evaporation.

The IEM and BEM trends differ systematically during the dry seasons as a result of the different $\mathrm{AE}$ mechanisms that activate as soon as significant drying processes cause AE to diverge from PE (see Sect. 3.1). The minimum WS values predicted by the two models during the dry periods are different, as already observed in the results meant to fit the data for the physical model (Fig. 13a). However, differences in minimum values are now higher than those previously computed, essentially due to the different domain thicknesses analysed ( $2 \mathrm{~m}$ instead $0.75 \mathrm{~m}$ ). The $0.75 \mathrm{~m}$ domain is so small that the meteorological forcing typical of the dry periods produces water content to attain residual value throughout the whole thickness. Most of the drying processes (WS reductions) occur when $\mathrm{AE}=\mathrm{PE}$. Only a residual part of the WS (from the point of departure down to the minimum) occurs because of internal evaporation. Under these conditions, IEM and BEM effectively work in a similar way most of the time, producing a small gap at the lowest WS. A $2 \mathrm{~m}$ thick domain, under the effects of similar meteorological forcing, does not achieve residual water content at all depths during the dry season. WS losses regulated by internal evaporation are far from minor and represent a significant part of the evaporated water, so that a significant gap is present at the lowest WS. This is around $150 \mathrm{~mm}$ for the years characterized by matching WS during the wet season.

WS gaps attained during the dry season are reflected in WS differences during the subsequent wet season (autumn), when landslide susceptibility is usually moderate. These differences tend to be gradually attenuated with the passing of time due to the higher potential infiltration in the IEM domain caused precisely by its drier state: the WS trend yielded by IEM is marked by higher hydraulic gradients. In some seasons, IEM predictions always remain below those of the $\mathrm{BEM}$, while in others the WS gaps disappear. The occurrence 
of one or the other condition depends essentially on rainfall cumulating over the autumn wet season. When the IEM prediction and the BEM match, AE will become equal to PE, so that IEM and BEM predictions coincide over the entire subsequent wet period. This happened during the 4 consecutive hydrological years from September 2002 to the August 2006 landslide, including the landslide year.

A peak at record is yielded by both IEM and BEM analyses at the time of the landslide (Fig. 15a). By enlarging the scale and looking at high WS values in order to isolate and highlight peaks (Fig. 15b), it may be observed that the peaks attained at the time of the landslide are higher than the peaks attained over other years. This encourages the assumption that both predictions, as they clearly indicate a peculiarity in the hydrological response in the cover at the time of the landslide, would have worked satisfactorily if they had been adopted as predictive tools in an early warning system. In fact, they would have been able to indicate a situation of alarm at the time of the landslide without generating a significant number of false alarms if the alarm threshold had been placed slightly below the peak attained at the landslide time.

Figure $15 \mathrm{c}$ and $\mathrm{d}$ show the IEM and BEM predictions for the evolution of suction at a depth of $1 \mathrm{~m}$. They reveal that suction predicted also at the middle of the layer may work as a proxy for slope safety conditions, as the hydrological behaviour it depicts is consistent with everything indicated by the integral variable WS. Suction or WS may therefore both be used as reference variables for early warning.

Figure $15 \mathrm{a}$ and $\mathrm{b}$ show the water storage evolution yielded by the simplest model (NEM) adopted, which neglects evaporation entirely (Pagano et al., 2010; Reder et al., 2017). In this case, it is not possible to carry out a continuous analysis of the hydrological response of the cover over the entire 10 years due to the inability of the model to predict water losses from the domain during the dry periods. Analysis needs to be restarted at the beginning of each hydrological year in order to reinitialize the hydraulic variables. Unfortunately, these become additional input data that have to be set. It would be necessary, in theory, to monitor suction or water content in the field to quantify initial conditions. The initial quantification of suction has a particular impact on the reliability of the analysis during the periods of landslide susceptibility occurring not far from the start time (considered at the beginning of the hydrological year). The effects of the starting conditions are in fact lost after a period of around 4 months (Pagano et al., 2010). In these predictions, suction value at the beginning of each hydrological year should be provided by field monitoring. Due to unavailability of monitoring data, suction re-initialization at the beginning of each hydrological year is achieved by adopting suction values yielded by the IEM. The NEM prediction has a peak at the time of the landslide, once again at record levels both in terms of water storage and suction. The peak is, however, not as high as a large number of other significant peaks. From the point of view of performance, NEM by itself must therefore be considered less effective than the IEM and BEM predictions together.

The performances of the three adopted approaches can be judged by taking the number of alerts and alarms they would have yielded if they had been adopted as predictive tools in an early warning system within the specific reference period analysed. Differences in performance obviously depend on the levels at which the thresholds for water storage or suction are set to limit the different alert stages and spread the alarm. The alarm threshold can be identified by interpreting the landslide phenomenon by the models, referring to the prediction yielded by the most complete one (IEM) in terms of the lowest suction level not associated with a landslide (around $3.5 \mathrm{kPa}$ ). A possible pre-alarm alert level is $5 \mathrm{kPa}$, obtained by increasing the alarm threshold by around $50 \%$. This double choice permits a quantitative comparison of model performance, with the IEM performing the best, returning 0 alarms and 1 alert ( 1 every 11 years). The BEM comes second, returning 3 false alarms ( 1 every 3.7 years) and 5 alerts ( 1 every 2.2 years). The NEM performs worst, returning 5 false alarms ( 1 every 2.2 years) and 12 alerts ( 0.9 for year).

\section{Conclusions}

This paper has investigated the performance of three physically based models taken from the literature with a view to using them for early warning predictions. Two of them incorporate evaporative fluxes, but the other neglects them. Particular care has been taken with the simplification of the models so as to respect the accuracy of the predictions they provide, establishing procedures to calibrate the parameters and to characterize the hydrological patterns they predict. The models' performance has been assessed by using them to interpret the case history of a landslide and examine their ability to indicate any hydrological peculiarity at the time of the landslide.

In analysing model performances, this work structures an entire procedure for early warning prediction. It is based on the following key points:

1. the assumption of WS or, alternatively, suction as proxies of slope safety evolution, overcoming the huge problems of characterizing complex strength factors and dealing with aleatory and undetectable local conditions that might generate landslide trigger;

2. the quantification of soil parameters at a mesoscale level by interpreting experimental results from a $1 \mathrm{~m}^{3}$ large layer subject to realistic boundary conditions rather than, as usual, from small laboratory specimens subject to artificial boundary conditions;

3. an experiment typology and theoretical interpretation procedures for parameter calibration; for all contexts 
similar to that here analysed (homogeneous layers made of soils similar to that investigated), parameter values provided are ready for use and, thus, they could greatly simplify the task of setting an early warning prediction;

4. the assumption of one-dimensionality of water flux, able to save time by preserving, at the same time, prediction reliability.

Regarding point 4 , the comparison between typical thickness of quite homogeneous pyroclastic covers and slope length make reliable the 1-D assumption, even if the features of actual flow might locally depart from those ideally hypothesized. This could be due to local inhomogeneity difficult to detect or specific hydrological conditions of lateral diversion. These local conditions, although they could represent a cause for local triggering, should however not affect the average suction levels that, yielded by a 1-D hypothesis, predispose the slope to propagate a local triggering.

The study shows that all models taken into consideration, if used as early warning predictive tools, would then be able to signal the alarm at the time of a landslide. Increased complexity and completeness of the models, however, would clearly result in a lower number of false alarm predictions.

The calibrated models, along with the detected thresholds, may be adopted as predictive tools in early warning systems for the numerous slopes with similar physical characteristics (slope gradient, slope thickness, intrinsic and state soil properties, vegetation), requiring site monitoring of, at least, hourly precipitations, daily air temperature and relative humidity.

The following limitations should, however, be highlighted in order to prevent from referring the same procedure to inappropriate contexts:

a. At present, the procedure may be confidentially applied to homogeneous sloping layers made of non-plastic silty volcanic soils. The possibility for extending it to other contexts has to be preliminarily investigated. This work and other literature findings encourage extending the procedure to all contexts susceptible to rainfall-induced landslides.

b. The one-dimensional assumption is validated for a homogeneous layer. This approach is quite established in literature but in layered contexts the proposed procedure should be carefully validated.

c. The hydraulic hysteresis of the soil has been neglected in the present study by assuming a unique SWCC fitting all the available observations over the calibration time span. The accuracy loss of the prediction due to this simplification is at present topic of new research. d. The assumed lowermost boundary condition (seepage surface) might be not realistic in contexts differing from that here considered. For instance, fractured formations filled with fine material transported from downward flux should be more appropriately analysed by assuming a unit gradient or infinite layer condition.

As concerns the setting of early warning thresholds, the implementation of the procedure could face, in several cases, with the unavailability of meteorological evolutions associated with landslides. In such a case, first trial thresholds in terms of suction or WS might be fixed conservatively on the base of the lowest suction levels (highest WS) ever predicted in converting the real meteorological evolution. In contrast, among the several meteorological evolutions available some of them could relate with a landslide. It is worth noting at this point that even a single well-documented case, as it was for the present study, represents a very lucky circumstance. The first trial alarm thresholds may then be based on suction or WS levels predicted at landslide time. In both circumstances (availability or not of a landslide case study), initial calibrated thresholds should be continuously validated and, eventually, updated over time as the site of interest could be subject to substantial geomorphological modifications affecting, in increase or decrease, its susceptibility to rainfallinduced landslides.

For monitored sites, a more accurate calibration and validation procedure could also be based on fitting monitored quantities.

Data availability. The data used in this research can be made available on demand. Please contact the authors for requests.

Competing interests. The authors declare that they have no conflict of interest.

Special issue statement. This article is part of the special issue "Landslide early warning systems: monitoring systems, rainfall thresholds, warning models, performance evaluation and risk perception". It is not associated with a conference.

Acknowledgements. Alfredo Reder and Luca Pagano have partly developed this work within the framework of the PRIN 2015 project titled "Innovative Monitoring and Design Strategies for Sustainable Landslide Risk Mitigation". They wish to thank the Ministero dell'Istruzione dell'Universitá e della Ricerca Scientifica (MIUR), which funded this project.

Edited by: Samuele Segoni

Reviewed by: three anonymous referees 


\section{References}

Allen, R. G., Pereira, L. S., Raes, D., Smith, M., and Ab, W.: Crop evapotranspiration - Guidelines for computing crop water requirements, FAO Irrigation and Drainage Paper 56, FAO, Rome, http://www.fao.org/docrep/X0490E/X0490E00.htm (last access: February 2018), 1998.

Allen, R. G., Pruitt, W. O., Raes, D., Smith, M., and Pereira, L. S.: Estimating evaporation from bare soil and the crop coefficient for the initial period using common soils information, J. Irrig. Drain. Eng., 131, 14-23, https://doi.org/10.1061/(ASCE)07339437(2005)131:1(14), 2005.

Al Qadad, A., Shahrour, I., and Rouainia, M.: Influence of the soil-atmosphere exchange on the hydric profile induced in soilstructure system, Nat. Hazards Earth Syst. Sci., 12, 2039-2049, https://doi.org/10.5194/nhess-12-2039-2012, 2012.

An, N., Hemmati, S., and Cui, Y. J.: Numerical analysis of soil volumetric water content and temperature variations in an embankment due to soil-atmosphere interaction, Comput. Geotech., 83, 40-51, https://doi.org/10.1016/j.compgeo.2016.10.010, 2017.

Arnone, E., Noto, L. V., Lepore, C., and Bras, R. L.: Physicallybased and distributed approach to analyze rainfall-triggered landslides at watershed scale, Geomorphology, 133, 121-131, https://doi.org/10.1016/j.geomorph.2011.03.019, 2011.

Baum, R. L. and Godt, J. W.: Early warning of rainfall-induced shallow landslides and debris flows in the USA, Landslides, 7, 259272, https://doi.org/10.1007/s10346-009-0177-0, 2010.

Baum, R. L., Savage, W. Z., and Godt, J. W.: TRIGRS - A FORTRAN program for transient rainfall infiltration and grid-based regional slope stability analysis, vers. 2.0, US Geol. Survey Open-File Rep. 2008-1159, 75 pp., US Geological Survey, Reston, Virginia, https://pubs.usgs.gov/of/2008/1159/ (last access: February 2018), 2008.

Bennett, N. D., Croke, B. F. W., Guariso, G., Guillaume, J. H. A., Hamilton, S. H., Jakeman, A. J., Marsilli-Libelli, S., Newham, L. T. H., Norton, J. P., Perrin, C., Pierce, S. A., Robson, B., Seppelt, R., Voinov, A. A., Fath, B. D., and Andreassian, V.: Characterising performance of environmental models, Environ. Model. Softw., 40, 1-20, https://doi.org/10.1016/j.envsoft.2012.09.011, 2013.

Brand, E. W., Premchitt, J., and Phillipson, H. B. Relationship Between Rainfall and Landslides in Hong Kong, in: Proc. 4th Int. Symp. on Landslides, Vol. 1, Toronto, 377-384, 1984.

Briggs, K. M., Smethurst, J. A., Powrie, W., and O'Brien, A. S.: The influence of tree root water uptake on the long term hydrology of a clay fill railway embankment, Transport. Geotech., 9, 31-48, https://doi.org/10.1016/j.trgeo.2016.06.001, 2016.

Capparelli, G. and Versace, P.: FLaIR and SUSHI: two mathematical models for early warning of landslides induced by rainfall, Landslides, 8, 67-79, https://doi.org/10.1007/s10346-010-02286, 2011.

Casadei, M., Dietrich, W. E., and Miller, N. L.: Testing a model for predicting the timing and location of shallow landslide initiation in soil-mantled landscapes, Earth Surf. Process. Land., 28, 925950, https://doi.org/10.1002/esp.470, 2003.

Chatterjea, K.: Observations on the Fluvial and Slope Processes in Singapore and their Impact on the Urban Environment, PhD Thesis, National University of Singapore, Singapore, 1989.

Cui, Y. J., Lu, Y. F., Delage, P., and Riffard, M.: Field simulation of in-situ water content and temperature changes due to ground-atmospheric conditions, Géotechnique, 55, 557-567, https://doi.org/10.1680/geot.2005.55.7.557, 2005.

Damiano, E., Greco, R., Guida, A., Olivares, L., and Picarelli, L.: Investigation on rainwater infiltration into layered shallow covers in pyroclastic soils and its effect on slope stability, Eng. Geol., 220, 208-218, https://doi.org/10.1016/j.enggeo.2017.02.006, 2017.

de Riso, R., Budetta, P., Calcaterra, D., and Santo, A.: Riflessioni sul comportamento delle colate rapide non incanalate della Campania, alla luce delle conoscenze pregresse, in: Proceedings National Conference on "La Mitigazione del Rischio da Colate di Fango", 2-3 May 2005, Napoli, 81-92, 2007.

DigitalGlobe: http://www.earth.google.com, last access: 26 April 2012

Ebel, B. A., Loague, K., and Borja, R. I.: The impacts of hysteresis on variably saturated hydrologic response and slope failure, Environ. Earth Sci., 61, 1215-1225, https://doi.org/10.1007/s12665009-0445-2, 2010.

Endrizzi, S., Gruber, S., Dall'Amico, M., and Rigon, R.: GEOtop 2.0: simulating the combined energy and water balance at and below the land surface accounting for soil freezing, snow cover and terrain effects, Geosci. Model Dev., 7, 2831-2857, https://doi.org/10.5194/gmd-7-2831-2014, 2014.

Formetta, G., Rago, V., Capparelli, G., Rigon, R., Muto, F., and Versace, P.: Integrated Physically based system for modeling landslide susceptibility, Proced. Earth Planet. Sci., 9, 74-82, https://doi.org/10.1016/j.proeps.2014.06.006, 2014.

Formetta, G., Simoni, S., Godt, J. W., Lu, N., and Rigon, R.: Geomorphological control on variably saturated hillslope hydrology and slope instability, Water Resour. Res., 52, 4590-4607, https://doi.org/10.1002/2015WR017626, 2016.

Fredlund, D. G., Rahardjo, H., and Fredlund, M. D.: Unsaturated soil mechanics in engineering practice, John Wiley \& Sons, Inc., Hoboken, New Jersey, 2012.

Geo-Slope: Vadose Zone Modeling with VADOSE/W 2007: An Engineering Methodology, 3rd Edn., Calgary, Alberta, Canada, 344 pp., 2008.

Gitirana Jr., G. F. N.: Weather-Related Geo-Hazard Assessment Model for Railway Embankment Stability, PhD Thesis, University of Saskatchewan, Saskatoon, SK, Canada, 411 pp., 2005.

Greco, R., Comegna, L., Damiano, E., Guida, A., Olivares, L., and Picarelli, L.: Hydrological modelling of a slope covered with shallow pyroclastic deposits from field monitoring data, Hydrol. Earth Syst. Sci., 17, 4001-4013, https://doi.org/10.5194/hess-174001-2013, 2013.

Gupta, H. V., Kling, H., Yilmaz, K. K., and Martinez, G. F.: Decomposition of the mean squared error and NSE performance criteria: Implications for improving hydrological modelling, J. Hydrol., 377, 80-91, https://doi.org/10.1016/j.jhydrol.2009.08.003, 2009.

Iverson, R. M.: Landslide triggering by rain infiltration, Water Resour. Res., 36, 1897-1910, https://doi.org/10.1029/2000WR900090, 2000.

Krause, P., Boyle, D. P., and Bäse, F.: Comparison of different efficiency criteria for hydrological model assessment, Adv. Geosci., 5, 89-97, https://doi.org/10.5194/adgeo-5-89-2005, 2005.

Milly, P. C. D.: Moisture and heat transport in hysteretic, inhomogeneous porous media: A matric head based formulation and a numerical model, Water Resour. Res., 18, 489-498, https://doi.org/10.1029/WR018i003p00489, 1982. 
Montgomery, D. R. and Dietrich, W. E.: A physically based model for the topographic control of shallow landsliding, Water Resour. Res., 30, 1153-1171, https://doi.org/10.1029/93WR02979, 1994.

Morgenstern, N. R.: The Evaluation of Slope Stability A 25 Year Perspective, in: Proc. Stability and Performance of Slopes and Embankments II, Vol. 1, Berkeley, California, 1-26, 1992.

Mualem, Y.: A new model for predicting the hydraulic conductivity of unsaturated porous media, Water Resour. Res., 12, 513-522, https://doi.org/10.1029/WR012i003p00513, 1976.

Napolitano, E., Fusco, F., Baum, R. L., Godt, J. W., and De Vita, P.: Effect of antecedent-hydrological conditions on rainfall triggering of debris flows in ash-fall pyroclastic mantled slopes of Campania (southern Italy), Landslides, 13, 967-983, https://doi.org/10.1007/s10346-015-0647-5, 2016.

Nash, J. E. and Sutcliffe, J. V.: River flow forecasting through conceptual models, Part I: a discussion of principles, J. Hydrol., 10, 282-290, https://doi.org/10.1016/0022-1694(70)90255-6, 1970.

Nicotera, M. V., Papa, R., and Urciuoli, G.: An experimental technique for determining the hydraulic properties of unsaturated pyroclastic soils, Geotech. Test. J., 33, 263-285, https://doi.org/10.1520/GTJ102769, 2010.

Pagano, L., Rianna, G., Zingariello, M. C., Urciuoli, G., and Vinale, F.: An early warning system to predict flowslides in pyroclastic deposits, in: Proceedings of the 10th International Symposium on Landslides and Engineered Slopes, 30 June-4 July 2008, Xi'an, China, Taylor \& Francis Group, London, 1259-1264, 2008a.

Pagano, L., Zingariello, M. C., and Vinale, F.: A large physical model to simulate flowslides in pyroclastic soils, in: Unsaturated Soils: Advances in Geo-Engineering - Proceedings of the 1st European Conference on Unsaturated Soils, E-UNSAT 2008, 2-4 July 2008, Durham, UK, 111-115, 2008b.

Pagano, L., Picarelli, L., Rianna, G., and Urciuoli, G.: A simple numerical procedure for timely prediction of precipitation-induced landslides in unsaturated pyroclastic soils, Landslides, 7, 273 289, https://doi.org/10.1007/s10346-010-0216-x, 2010.

Pagano, L., Reder, A., and Rianna, G.: Processi di infiltrazione ed evaporazione nei terreni piroclastici illustrati attraverso la selezione di alcuni eventi rappresentativi, Rivista Italiana Geotecnica, 1, 62-76, 2014.

Papa, R., Pirone, M., Nicotera, M. V., and Urciuoli, G.: Meccanismi di innesco di colate di fango in piroclastiti parzialmente sature, in: Proc. 1st Italian Workshop on Landslides, Napoli, edited by: Picarelli, L., Tommasi, P., Urciuoli, G., and Versace, P., 2, 91106, 2009.

Pirone, M.: Analysis of slope failure mechanism in unsaturated pyroclastic soils, based on testing site monitoring $\mathrm{PhD}$ thesis, University of Naples, Federico II, Naples, Italy, 2009.

Pirone, M., Papa, R., Nicotera, M. V., and Urciuoli, G.: Soil water balance in an unsaturated pyroclastic slope for evaluation of soil hydraulic behaviour and boundary conditions, J. Hydrol., 528, 63-83, https://doi.org/10.1016/j.jhydrol.2015.06.005, 2015a.

Pirone, M., Papa, R., Nicotera, M. V., and Urciuoli, G.: In situ monitoring of the groundwater field in an unsaturated pyroclastic slope for slope stability evaluation, Landslides, 12, 259-276, https://doi.org/10.1007/s10346-014-0483-z, 2015b.

Pirone, M., Rianna, G., Reder, A., Pagano, L., and Urciuoli, G.: Two Applications of Soil Water Balance in Un- saturated Pyroclastic Soils, Proced. Eng., 158, 188-193, https://doi.org/10.1016/j.proeng.2016.08.427, 2016.

Rahardjo, H., Li, X. W., Toll, G., and Leong, C.: The effect of antecedent rainfall on slope stability, Geotech. Geol. Eng., 19, 371399, https://doi.org/10.1023/A:1013129725263, 2001.

Rahimi, A., Rahardjo, H., and Leong, C.: Effect of Antecedent Rainfall Patterns on Rainfall-Induced Slope Failure, J. Geotech. Geoenviron. Eng., 137, 483-491, https://doi.org/10.1061/(ASCE)GT.1943-5606.0000451, 2011.

Reder, A., Pagano, L., Picarelli, L., and Rianna, G.: The role of the lowermost boundary conditions in the hydrological response of shallow sloping covers, Landslides, 14, 861-873, https://doi.org/10.1007/s10346-016-0753-z, 2017.

Rianna, G., Pagano, L., and Urciuoli, G.: Rainfall patterns triggering shallow flowslides in pyroclastic soils, Eng. Geol., 174, 22 35, https://doi.org/10.1016/j.enggeo.2014.03.004, 2014a.

Rianna, G., Pagano, L., and Urciuoli G.: Investigation of soilatmosphere interaction in pyroclastic soils, J. Hydrol., 510, 480 492, 2014b.

Rianna, G., Reder, A., Pagano, L., and Comegna, L.: Hysteresis processes and effective rainfall histories, in: Advances in Landslide Understanding, edited by: Alonso, E. and Pinyol, N., International Center for Numerical Methods in Engineering (CIMNE), Barcelona, Spain, 60-63, 2017.

Richards, L. A.: Capillary conduction of liquids through porous mediums, J. Appl. Phys., 1, 318-333, https://doi.org/10.1063/1.1745010, 1931.

Rosso, R., Rulli, M. C., and Vannucchi, G.: A physically based model for the hydrologic control on shallow landsliding, Water Resour. Res., 42, W06410, https://doi.org/10.1029/2005WR004369, 2006.

Shiozawa, S. and Campbell, G. S.: Soil thermal conductivity, Remote Sens. Rev., 5, 301-310, https://doi.org/10.1080/02757259009532137, 1990.

Šimunek, J., Van Genuchten, M. T., and Šejna, M.: The HYDRUS software package for simulating two-and three-dimensional movement of water, heat, and multiple solutes in variablysaturated media, Technical manual, version 1, PC Progress, Prague, Czech Republic, 241 pp., 2006.

Song, W. K., Cui, Y. J., Tang, A. M., Ding, W. Q., and Wang, Q.: Experimental study on water evaporation from compacted clay using environmental chamber, Can. Geotech. J., 53, 1293-1304, https://doi.org/10.1139/cgj-2015-0415, 2016.

Tetens, O.: Uber einige meteorologische begriffe, Z. Geophys., 297-309, 1930.

van Genuchten, M. T.: A closed form equation for predictiong the hydraulic conductivity, Soil Sci. Soc. Am. J., 44, 892-898, https://doi.org/10.2136/sssaj1980.03615995004400050002x, 1980.

Wilson, G. W., Fredlund, D. G., and Barbour, S. L.: Coupled soilatmosphere modeling for soil evaporation, Can. Geotech. J., 31, 151-161, https://doi.org/10.1139/t94-021, 1994.

Wilson, G. W., Fredlund, D. G., and Barbour, S. L.: The effect of soil suction on evaporative fluxes from soil surfaces, Can. Geotech. J., 34, 145-155, https://doi.org/10.1139/t98-034, 1997. 